\title{
OFERTA DE ARROZ NO URUGUAI
}

\author{
MARTIN JUAN DABEZIES ANTIA
}

Orientador: Prof. Dr. JOSÉ fERREIRA DE NORONHA

Dissertação apresentada à Escola Superior de Agricultura "Luiz de Queiroz", da Universidade de São Paulo, para obtenção do título de Mestre em Agronomia. Área de Concentração: Economia Agrária.

PIRACICAB A

Estado de São Paulo - Brasil

Junho - 1987 
A todos que tornaram possível que eu chegasse até aqui, especialmente a minha companheira Silvia e a meus filhos Juan Martin, Maria Jesūs e ........ dedico este trabal ho. 


\section{AGRADECIMENTOS}

Ao Ministerio de Agricultura, Ganaderia y Pesca do Uruguai e à Organização das Nações Unidas para Agricultura e Alimentação pela oportunidade e financiamento para realizar o Curso de Pós-Graduação.

Aos companheiros da Dirección de Programación y Politica Agropecuaria pelo apoio na conclusão desta dissertação.

Aos companheiros de curso pela sua amizade.

Ao Professor José Ferreira de Noronha pela sua orientação.

Aos professores do Departamento de Economia e Sociologia Rural, especialmente a Geraldo Sant'Ana de Camargo Barros, Zilda Paes de Barros Mattos e Rodolfo Hoffmann pela sua colaboração e sugestões.

Aos funcionärios do Departamento de Economia e Sociologia Rural, que direta ou indiretamente colaboraram durante o curso, especialmente a Marcia Maria Beltrame Correia, pela sua dedicação na fase de datilografia. 
SUMARIÓ

Pägina

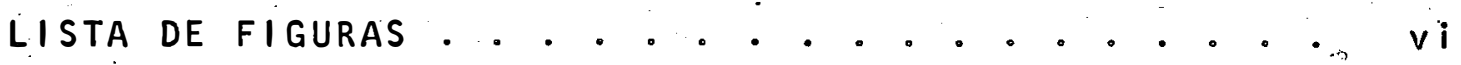

LISTA DE TABELAS . . . . . . . . . . . . . . . . . . vi $\mathbf{v}$

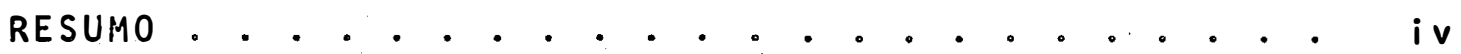

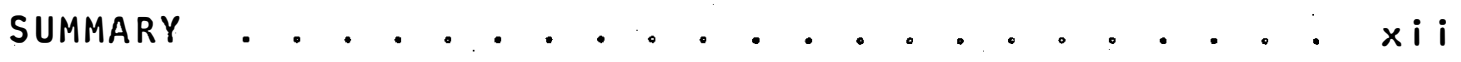

1. INTRODUÇÃO . . . . . . . . . . . . . . . . . . . . . . . 1

1.1. Importância da Cultura . . . . . . . . . 1

1.1.1. Condições naturais para a cultura .............. . . 3

1.1.2. Localização da cultura:. . . . . . 8

1.1.3. Organização da produção . . . . . . . 9

1.1.4. Tecnologia empregada . . . . . . . . 17

1.1.5. Destino da produção. . . . . . . 24

1.1.5.1. Mercado interno. . . . . . 24

1.1.5.2. Exportações . . . . . . 24

1.1.6. Políticas para o arroz . . . . . . 29

1.1.6.1. Política de preços... . 30

1.1.6.2. Política de crédito... . 31

1.1.6.3. Política tributäria .. . 31

1.1.6.4. Política tecnolögica.... 32

1.1.6.5: Política de comércio. exte-

rior........ $\cdot 32$

1.2. Importância dos Estudos de Oferta . . . . 33 
1.3. Objetivos......................... 34

2. METODOLOGIA $\because \ldots \ldots \ldots$

2.1. Aspectos Teóricos e Estimação Empírica ‘ . 36

2.2. Material .................... 41

2.3. Método . . . . . . . . . : : 41

2.3.1. Modelo envolvendo rigidez a curto prazo dos fatores............... 44

2.3.2. Estudo de não reversibilidade da função de oferta......... . . 57

3. RESULTADOS................. . . . 62

3.1. Modelo Simples de Ajustamento Parcial... 63

3.1.1. Ârea............ . . 63

3.1.2. Rendimento........... 66

3.2. Ajustamento Parcial com Variáveis Binárias. 69

3.2.1. Area . . . . . . . . . . 69

3.2.2. Rendimento. . . . . . . . . . 75

3.3. Hipótese de Não-Reversibilidade. . . . . . 76

3.4. Análise Econômica dos Resultados . . . . . 73

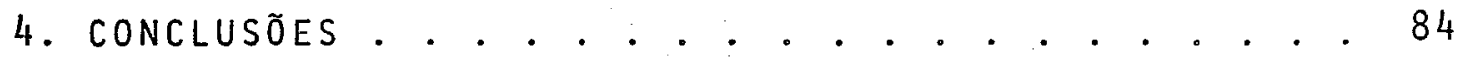

REFERENCIAS BIBLIOGRAFICAS . . . . . . . . . . . . . 87

APENDICE 1 . . . . . . . . . . . . . . . . . . 92

APENDICE 2 . . . . . . . . . . . . . . . . . . . 95 
Figura

Pägina

1 Areas Arrozāveis ... . . . . . . . . 7

2 Localização da cultura............ 10

3 Curvas de oferta de curto e longo prazo . . 45

4 Evolução dos rendimentos de arroz no Uruguai. 68

5 Evolução da ärea plantada no Uruguai . . . . 71

6 Preço real do arroz é área plantada por ano . 72 


\section{LISTA DE TABELAS}

Tabela

Pàgina

1 Terras de uso arroz-pecuäria, no Uruguai . . 6

2 Superfície e nümero de produtores arrozeiros . 14

3 Participação dos diferentes moinhos no processamento................... . . . 16

4 Evolução do uso de fertilizantes na cultura de arroz no Uruguai . . . . . . . . . . . . . 22

5 Evolução do uso de herbicidas na Região Leste . 23

6 Consumo anual e per capita de arroz branco no Uruguai, período 1972-1932 . . . . . . . . . 25

7 Consumo per capita para alguns países e regiões - 1950-52, 1961-63 e 1975........... . . 26

8. Produção e exportação de arroz no Uruguai, 1965

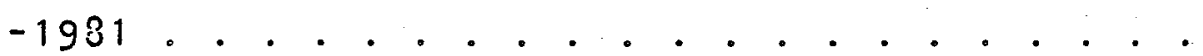

9 Estimativas de elasticidades-preço da ārea plan tada para o arroz no Uruguai pelo modelo de ajustamento parcial. Período 1956-1936 . . .

10. Estimativas de elasticidades-preço da ārea plan tada para o arroz no Uruguai pelo modelo de ajustamento parcial com variāveis binārias. Pe-

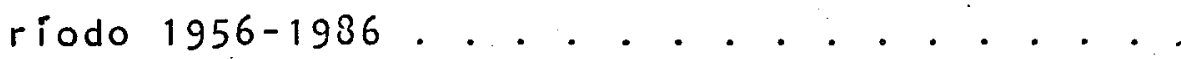

11 Estimativas de elasticidades-preço relativo de ärea plantada para o arroz no Uruguai pelo modelo de ajustamento parcial. Período 1956-1996 
12 Estimativas de elasticidades-preço calculadas por diferentes autores em diferentes anos... 


\section{OFERTA DE ARROZ NO URUGUAI}

Autor: MARTIN JUAN DABEZIES

Orientador: JOSE FERREIRA DE NOROUHA

RESUMO

o arroz, cultura de relevância no setor agropecuário e na economia do Uruguai, tem-se mostrado muito dinâmico nos ültimos vinte anos. Sua cultura e processamento geram um número elevado de empregos e são responsáveis por quase $10 \%$ do total das divisas provenientes das exportações do país.

A produção localiza-se fundamentalmente na Região Leste do país, na Bacia da Lagoa Mirim, em cultivos de àrea média de 200 hectares e com três agroindústrias com äreas médias de 2650 hectares ${ }^{1}$. O setor industrial comercial é muito concentrado, sendo que somente um moinho ē responsävel por $50 \%$ da produção.

Nos últimos dez anos tem-se observado uma mudança tecnológica de importância, que elevou os rendimentos de arroz para aproximadamente $5500 \mathrm{~kg} / \mathrm{ha}$.

Em face da sua importância, o conhecimento

1 Toda a produção de arroz no Uruguai é irrigada. 
das relaçöes estruturais da oferta de arroz è de grande preeminência na orientação das políticas, especialmente de preços, e no conhecimento da resposta dos produtores face a estímulos ou desestímulos que possam afetar a cultura.

Este estudo teve como objetivo analisar as relações de oferta agregada de arroz no Uruguai e estimar as elasticidades-preço de resposta de ärea plantada e rendimento agrícola, para o período 1956-86.

Para isso, empregou-se o modelo Nerloviano com expectativas estāticas de preço e suposta rigidez na mobilidade dos recursos, no curto prazo. As equações foram ajustadas pelo mētodo dos mínimos quadrados ordinärios. Tentou-se tambēm testar a hipótese de não-reversibilidade da função de ärea plantada.

Para a área plantada, os modelos estimados explicaram quase $99 \%$ das variações ocorridas. As elasticidades-preço para àrea colhida foram estimadas nas médias de todo o período sob estudo e para os períodios 1956-75, 1976-86 mediante a inclusão de variāveis binärias no modelo Nerloviano.

$$
\text { Para todo o período as elasticidades-preço }
$$
de curto prazo e longo prazo resultaram em 0,209 e. 1,101. Para o primeiro período as elasticidades-preço foram 0,49 e 1,978, e para o segundo de 0,07 e 0,28 para curto e longo prazo respectivamente. 
Os coeficientes de ajustamento indicam. que os produtores estimulados pelo preço ajustaram no māximo $25 \%$ da àrea desejada em um ano.

$\therefore \quad$ Os resultados obtidos neste estudo säo semelhantes aos encontrados por outros autores para o Brasil e outros países subdesenvolvidos.

Para rendimento, as equações ajustadas resultam em coeficientes incompativeis com a teoria e hipóteses bäsicás do estudo.

A hipōtese de não-reversibilidade não pode ser testada por problemas de especificação do modelo. 
RICE SUPPLY IN URUGUAY

Author: MARTIN JUAN DABEZIES

Adviser: JOSE FERREIRA DE NORONHA

SUMMARY

Rice has become a very importantagricultural product in Uruguay economy, with significant changes in the last twenty years. It is an important source of employment and it is responsible for nearly ten per cent of Uruguaian exports.

The production is concentrated in the East Region of the country, in the Bacin of Mirim's Lagoon. Average farm sizes 200 hectares, except for three agroindustries with average of 2650 hectares. Industrialization of rice is very concentrated. One industrial establishment alone, is responsible for fifty per cent of the production.

Important changes in cultivation tecnology have occurred during the last decade. Yields increased from 4000 to $5500 \mathrm{~kg} / \mathrm{ha}$.

Because of the importance of rice production to the Uruguayan economy, understanding rice supply relations has become crucial for price policy. 
The objective of this research, is to analyse rice supply relationships in Uruguay and to estimate price elasticities, both for acreage and yield, using a time series data, for the period 1956-1936.

A Nerlovian model was used. Supply functions were adjusted to the data by the ordinary least square method. The hypotesis of non-reversibility function was also tested, using the HOUCK especification.

The cultivated-area model used in this study, explained ninety-nine per cent of changes in area.

The price-elasticity of the planted area, was calculated at the means of the variables, for the whole period and for the periods 1956-1975 and 1976-1996, using dummy variables in the Nerlovian model.

For the whole period price-elasticities for short and long run were 0.209 and 1.101 respectively. For the first period price-elasticities were 0.49 and 1.978 , and for the second, 0.07 and 0.28 for short and long run respectively.

Adjustment coefficients show that farmers, estimulated by prices, were able to adjust twenty-five per cent of the area to be cultivated in one year.

For yields, the equations used resulted in coefficients that are not compatible with the theory and the hypotesis formulated. 
xiv

Non-reversibility hypotesis was not

adequately tested because of miss specification of the model.

The results of this research, are

reasonably similar to those of other authors in Brazil and other developing countries. 
1. INTRODUÇ尺̃OO

1.1. Importância da Cultura

os primeiros intentos de cultivar o arroz no país remontam-se a finais do século passado, embora somente depois de 1930 a cultura começou a se tornar comercial dando origem aos primeiros moínhos. De 1935 em diante, logra-se o auto abastecimento do mercado interno; a cultura expande-se de forma sustentada e a partir da década de 50 passam a ser exportados grãos em quantidades significativas.

Nas duas ültimas décadas, a produção de arroz apresenta um marcado dinamismo em contraste com o resto da atividade agrícola. Desde 1960 até o presente, a produção deste cereal multiplica-se por sete, alcançando em torno de $400 \mathrm{mil}$ toneladas nos ültimos anos. Este crescimento deve-se à grande expansão na área, que quase triplica-se, cultivando-se na atualidade, perto de $80 \mathrm{mil}$ hectares $\mathrm{e}$, em menor medida ao incremento nos rendimentos físicos, com valor médio de $4850 \mathrm{~kg} / \mathrm{ha}$ nos ültimos 6 anos.

A ärea semeada com arroz representa $0,5 \%$ da superfície do Uruguai. Usam-se solos planos e baixos que a- 
presentam alta produtividade com arroz, sendo pobre a capacidade para a maioria das demais atividades agropecuárias.

Em média, estima-se que a cultura ocupa uma pessoa a cada 15 hectares e um profissional cada 800 hectares. Como referência, indica-se que a média para o país è de um trabalhador para cada 100 hectares. Incluindo as pessoas ocupadas no transporte e na indüstria, obtem-se aproximadamente 8.500 pessoas diretamente ocupadas na produção e beneficiamento de arroz segundo a Associação de Cultivadores de Arroz (ACA). E importante salientar, que as características desta atividade resultou na necessidade de serviços de apoio, que demandou força de trabalho, pelo que a ocupação gerada è muito maior que os valores apresentados. Os serviços e as obras de infraestrutura (caminhos, obras para irrigação e drenagem, secagem e armazenagem do grão), também tem um importante efeito de dinamização regional.

A produção de arroz requer alto nivel de investimento por unidade de superfície; o capital investido em um hectare de arroz é doze vezes maior do que o necessārio para a exploração de pecuäria tradicional ( $A C A$ ).

0 valor da produção obtido em um hectare de arroz. é cerca de 38 vezes maior ao alcançado en um hectare de pastagem; e três vezes superior ao que se obtém em média pela agricultura extensiva (ALONSO, 1932).

Em. termos de geração de divisas, o arrozé su- 
perior em 50 vezes à pecuāria extensiva. Embora os requerimentos de divisas sejam bem maiores, o balanço é claramente favorävel ao arroz. Estimativas feitas por STENERI para o ano de 1984 , resultou em um balanço positivo de três dólares americanos para cada dolar utilizado na produção. Este fato tem muita importância, uma vez que mais de $80 \%$ da produção è exportada.

Resumindo, a receita bruta arrozeira tem superado nos últimos anos de outras culturas e tem representado quase $12 \%$ da receita bruta agrícola; o valor das exportações tem oscilado entre $\quad 60$ e $100 \mathrm{milhões} \mathrm{de} \mathrm{dölares,}$ isto é, quase $10 \%$ das exportações totais do país.

1.1.1. Condições naturais para a cultura

0 arroz é uma cultura bastante difundida a nivel mundial. Embora pareça naturalmente adaptado às condições tropicais de altas temperaturas e umidade, os maiores rendimentos por unidade de superfície são obtidos nasregiões temperadas. A menor temperatura, em particular as baixas temperaturas noturnas, são consideradas condições favoráveis. para a acumulação de reservas no grão.

o pais, particularmente a Bacia da Lagoa Mirim, tem um clima adequado para a cultura do arroz. A temperatura média é de $20,4^{\circ} \mathrm{C}$ durante a estação de cresci- 
mento, setembro a abril, a luminosidade ë perto de 2000 horas de sol e a precipitação mëdia anual ë de $1.128 \mathrm{~mm}$.

Segundo CORSI (1982) o arroz è.uma. cultura que cresce bem em regiões que tem temperatura média superior a $20^{\circ} \mathrm{C}$ durante a estação de crescimento e, para ter eficiência tērmica, a temperatura māxima mēdia do mês mais quente deve ser superior a $25^{\circ} \mathrm{C}$. E assim que o autor coloca a totalidade do país na zona preferencial de aptitude tērmica para o desenvolvimento da cultura. No entanto, a média. de longos períodos não exprime fielmente as condições climāticas do Uruguai. Assim, tem-se primaveras chuvosas ou excessivamente secas e no verão podem acontecer prolongadas estiagens; a temperatura pode igualmente variar grandemente de um ano para outro. Tudo isto traz conseqüências negativas no que se refere à data de semeadura, manejo da cultura, ao crescimento da mesma, à disponibilidade de mäquinas necessärias, à quantidade de àgua disponível para rega e, finalmente, nos rendimentos. A variabilidade dos rendimentos em torno da tendência pode ter origem na mencionada variabilidade climätica, porém, o fato de ser uma cultura irrigada, atenua em muito o que sucede no Uruguai com outras culturas extensivas.

Estudos feitos por CHEBATAROFF (1980) apontam que no país dão-se variações importantes na duração das horas luz e a floração tem lugar com o encurtamento dos dias. 
o melhor seria que a floração coincidisse com o período de māxima isolação, mas a época de semeadura é de outubro em diante, uma vez que a cultura requer no minimo $15^{\circ} \mathrm{C}$ no solo. Este autor localiza o Uruguai em uma posição intermediāria, do ponto de vista climático, comparando com duas das principais zonas de produção do arroz no mundo: Sapporo, no Japão, a $43^{\circ}$ de latitude norte, e Los Baños, nas Filipinas, a 140 de latitude norte.

Em síntese, as condições climäticas do país não são limitantes para o desenvolvimento de um ciclo produ tivo anual em ótimas condições, embora não seja possível a policultura anual e tambēm a cultura sem irrigação. 0 arroz é todo irrigado no Uruguai.

A dotação dos solos aptos para arroz è.alta. Sem levar em consideração a disponibilidade de àgua, tem-se detectado quase um milhão e meio de hectares de uso pastoril -arrozävel (Tabela l e Figura l), das quais perto de $600 \mathrm{mil}$ são aräveis. Do total desta superfície, $382 \mathrm{mil}$ hectares localizam-se na bacia da Lagoa Mirim; 135 mil na zona centro em torno do Rio Tacuarembó e seus afluentes, e os restantes repartem-se entre o norte e as àreas tradicionalmente agricolas do litoral e sul. 
Tabela 1. Terras de uso arroz-pecuäria, no Uruguai.

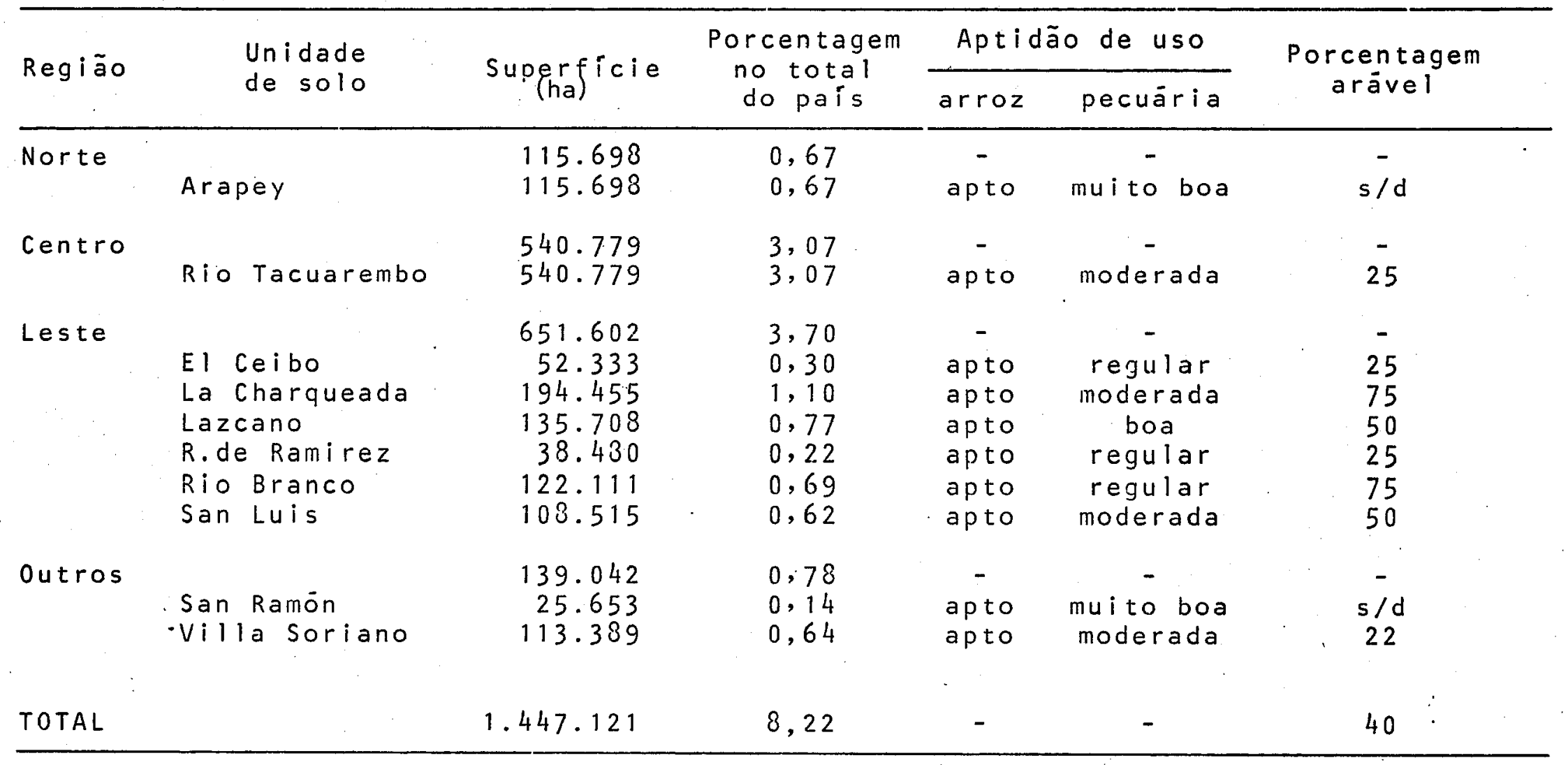

Fonte: Dirección de Suelos y Fertizizantes (DSF) - Ministério de Agricultura y Pesca (MAP). 


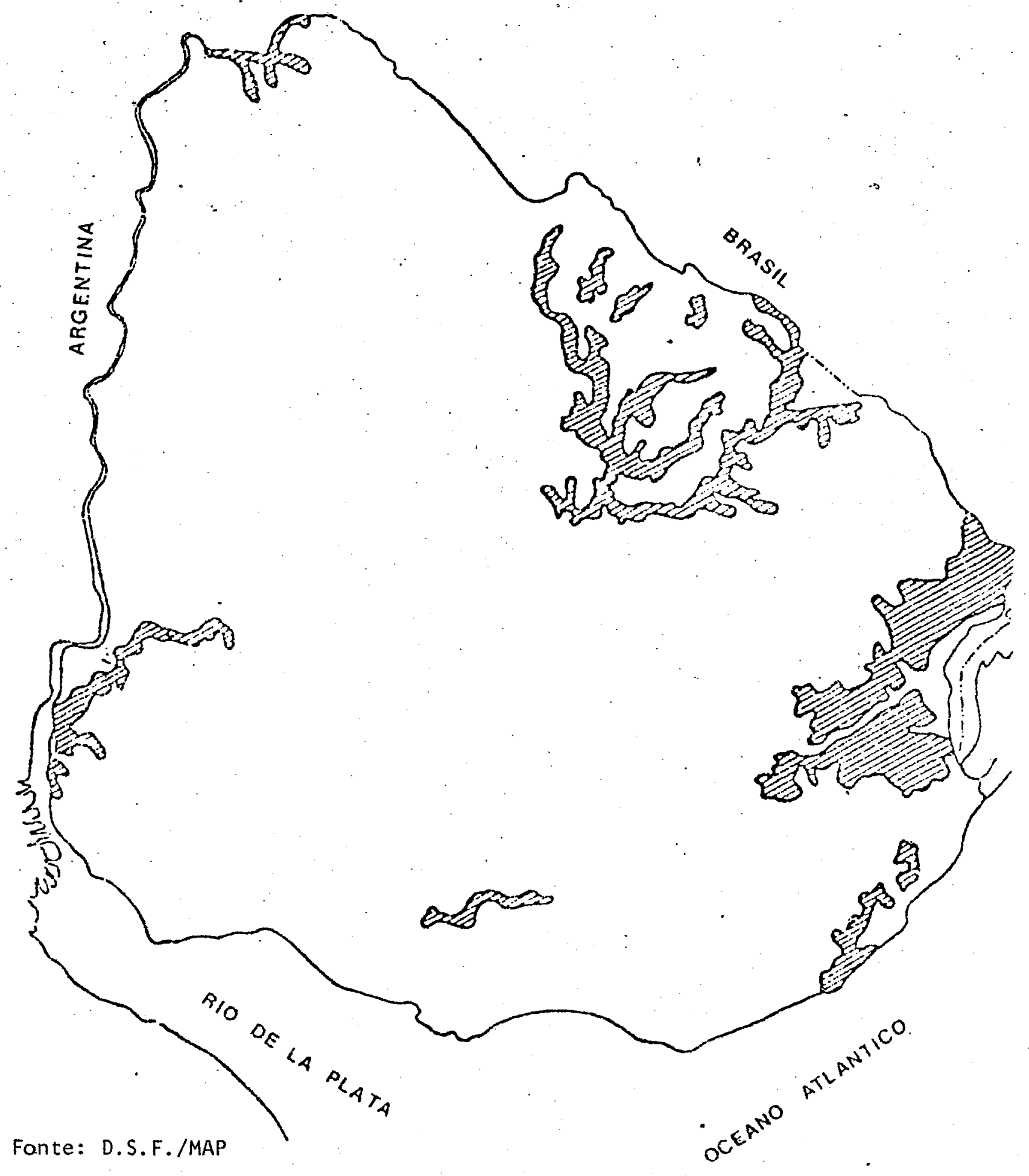

Figura 1. Áreas arrozāveis (äreas achuradas no mapa). 
Um aspecto a destacar, è que grande proporção dos solos arrozāveis jă foram utilizados, não tendo assim, suas caracteristicas originais. Na bacia da Lagoa Mirim $80 \%$ da área já foi usada alguma vez com arroz.

Os solos, então, não seriam a limitação para a expansão da cultura, o mesmo não acontecendo com a àgua. A quantidade de ägua necessäria é de $15.000 \mathrm{~m}^{3}$, dos quais dois terços devem ser abastecidos pela irrigação. Embora o país possua uma rede hidrográfica muito ampla, o volume de água requerido para fornecer as necessidades, só se encontra naturalmente em cursos de importancia ou lagoas. Tradicionalmente a irrigação é efetuada por bombeamento, o que obriga a cultura estar localizada nas proximidades das referidas fontes de àgua.

Estudos feitos para as principais bacias, determinam a existência de boas disponibilidades de ägua àcondição de serem feitas importantes obras de represamento e sistematização.

1.1.2. Localização da cultura

Levando em consideração os requerimentos da cultura em topografia, solos e água, a mesma localiza-se em três regiões bem definidas (Figura 2):

- A Região norte; culturas desenvolvidas nos 
departamentos de Artigas e Salto, tomando ägua dos rios Cuareim, Uruguai e seus afluentes.

- A Região centro; nos departamentos de Tacuarembó e Rivera, usando como fonte de ägua o Rio Tacuarembō e afluentes.

- A Região leste; nos departamentos de Cerro Largo, Treinta y Tres, Lavalleja e Rocha. A regiãoforma parte da bacia da Lagoa Mirim; constitui uma extensa áres de planícies com inclinação suave para a lagoa sulcada por muitos rios entre eles Yaguaron, Tacuarí, Cebollati, 0limar e outros menores. A Lagoa Mirim é a principal e mais segura fonte de àgua. Esta região, pela extensão alcançada pela cultura e por sua potencialidade, é sem dūvida, a mais importante.

1.1.3. Organização da produção

No princípio do sēculo existiam no país alguns moinhos que processavam arroz comprado no exterior e a produção resultante abastecia o mercado interno. Como já foi mencionado, o arroz começou a șer cultivado no Ijruguai em 1930, por parte de empresas agroindustriais que também industrializavam o grão. No começo, estas empresas co-existiam com os antigos moinhos e toda a produção era destinada ao mercado interno.

1 Equivalente a Estados no Brasil. 
10.

$\therefore::$ àreas de arroz

...- limites departanentais

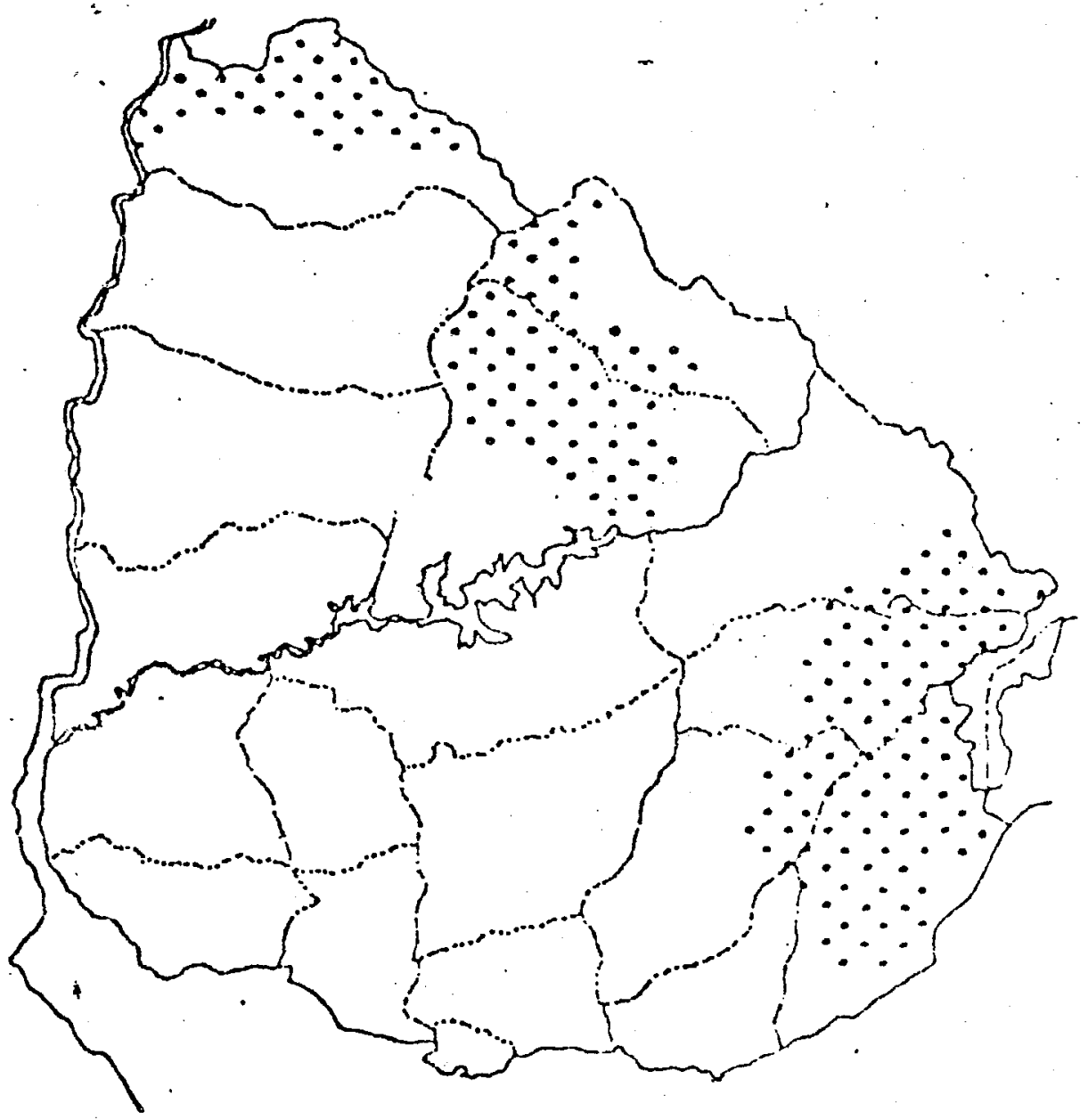

Figura 2. Localização da cultura. 
Durante a década de 40 , apareceram moinhos que processavam arroz de estabelecimentos agropecuārios dispersos. E um período de grande expansão em que cresce $\circ^{\circ}$ numero de moinhos e produtores rurais. Depois deste -período de crescimento, segue-se na segunda metade da década de 50 , uma etapa de forte concentração, onde os moinhos começam a prestar uma sērie de serviços. para lograr melhor resultado econômico, assegurando matēria-prima. Durante esta época desaparecem várias empresas pequenas e saem fortificadas um nümero reduzido de maiores.

$$
\text { A confrontação entre os moinhos e }
$$

entre grandes empresas industriais e produtores, origina a aparição de. empresas cooperativas que se consolidam nos anos 60. Estas cooperativas encaminham-se à exportação, uma vez que o mercado interno era abastecido por empresas que possuiam marcas conhecidas a nivel de consumidor nacional. Atē esse momento, o mercado interno oferecia mais segurança de colocação de produção a preços remuneradores, visto que a expansão do setor efetua-se em função do mercado interno.

Por ültimo, na década de 70 , processa-se uma nova estrutura do setor industrial com a desaparição de uma das empresas cooperativas e a passagem de outra a sociedade anônima. Paralelamente, dä-se uma grande expansão da produção por crescimento dos volumes exportados.

E de salientar que em fins dos anos 60 , ob- 
serva-se uma brusca mudança nas variedades de arroz produzidas e um grande esforço para melhorar a qualidade do produto, devido a exigência do segmento do mercado internacional, onde dirige-se a produção e que tem permitido a éxpansão das exportações. Este segmento é o de arroz longo de muito boa qualidade.

Durante o processo descrito, a produção e a industrialização permaneceram em mãos de capitais nacionais, o que permitiu que os ganhos ficassem dentro da sociedade. Porēm, até 1963, ano em que o Banco da República começou a oferecer crëdito, o sistema bancärio estrangeiro apropriava-se de parte dos ganhos gerados internamente.

No momento atual, o setor consolidou-se com a existência de algumas grandes empresas agroindustriais propriamente ditas, numerosos produtores agrícolas e umas poucas empresas industriais.

A nível agrícola, existem aproximadamente 320 produtores com ārea cultivada relativamente extensa, o que não é comum no resto do mundo. A àrea média, excluindo as empresas agroindustriais è de perto de 200 hectares de cultivo. Nas regiões norte e centro apresentam maior importância as produções pequenas, como conseqüência, a superfície média é inferior à nacional (Tabela 2). Na região leste co-existem dois tipos de produtores; as empresas agroindustriais e os que somente produzem arroz verde. No ano agrícola $31 / 32$, 
três empresas agroindustriais, com superfície média de 2644 hectares, controlavam $13,8 \%$ da superfície cultivada na região e $11,6 \%$ a nivel nacional. os produtores restantes da região, tinham superfícies médias de 236 hectares e foram responsáveis por $72,3 \%$ da produção nacional.

São comuns na produção arrozeira, formas precárias de posse da terra é água, como conseqüencia da mobilidade do produtor em procura de novas terras. Aproximadamen te $30 \%$ da àrea sob cultivo é realizada em terras próprias.

Pela elevada utilização de mão-de-obra assalariada, elevado nível de capitalização, grande vinculação com os mercados de insumos, produtos e de dinheiro; as empresas produtoras de arroz podem ser caracterizadas como tipicamente capitalistas.

No país existem 11 moinhos incluidas as agroindūstrias, encarregados de realizar o processo industrial e comercial. As 4 maiores processal $81,8 \%$ da produção, indicando al to grau de concentração na indūstria. Os moinhos pequenos trabalham na região norte; dos cinco maiores, COOPAR, ARROZAL 33 e CIPA trabalham somente na região leste, CASARONE e SAMAN, em todo o país. Todos são sociedades anônimas e muitos produtores participan como acionistas. 
Tabela 2. Superficie e nümero de produtores arrozeiros.

\begin{tabular}{|c|c|c|c|c|c|c|}
\hline \multirow{3}{*}{$\begin{array}{l}\text { Tamanho de } \\
\text { ärea de } \\
\text { arroz (ha) }\end{array}$} & \multicolumn{4}{|c|}{ Regiões } & \multirow{2}{*}{\multicolumn{2}{|c|}{ TOTAL }} \\
\hline & \multicolumn{2}{|c|}{ Leste } & \multicolumn{2}{|c|}{ Centro e norte } & & \\
\hline & ha & Produtores & ha & produtores & ha & produtores \\
\hline $1-40$ & 214 & 8 & 300 & 10 & 514 & 18 \\
\hline $40-200$ & 12.949 & 111 & 5.498 & 67 & 18.447 & 178 \\
\hline $200-450$ & 16.567 & 61 & 4.608 & 18 & 21.175 & 79 \\
\hline $450-1000$ & 15.364 & 27 & 607 & 1 & 15.971 & 23 \\
\hline $1000-2000$ & 4.458 & 3 & - & - & 4.458 & 3 \\
\hline SUB-TOTAL & 49.552 & 210 & 11.013 & 96 & 60.565 & 306 \\
\hline mais de & & & & & & \\
\hline $2.0001 /$ & 7.933 & 3 & - & - & 7.933 & 3 \\
\hline TOTAL & 57.485 & 213 & 11.013 & 96 & 68.498 & 309 \\
\hline
\end{tabular}


A empresa mais antiga è CIPA, que surgiu em 1928; seguiram-se ARROZAL 33, no inicio dos anos 30 e CASARONE em 1937. Em 1947, funda-se SAMAN e muito depois, em principios dos anos 60 , dois moinhos cooperativos: COOPAR e CAPARROZ; este último falido em 1979 mesmo ano em que COOPAR transforma-se em sociedade anônima.

A indūstria é fortemente concentrada. Uma empresa, SAMAN, controla mais de $50 \%$ da produção total; COOPAR controla $20 \%$; CASARONE e ARROZAL $33 \mathrm{com} 10 \%$ cada uma e CIPA com $3 \%$ (Tabela 3). A capacidade industrial instalada encontra-se saturada na atualidade. Esse fato é muito grave na etapa de secagem do grão, atividade totalmente centralizada, que se concentra em um período muito curto de tempo e não pode ser adiada sem riscos de grandes perdas.

Recentemente as cinco maiores indústrias as sociaram-se para a construção de uma fábrica de arroz parboilizado, ARROZUR S.A., com capacidade instalada de 40 mil toneladas. No marco desta integração, existem planos para a construção de uma fábrica de óleo. comestível de arroz Gremial de Molinos Arroceros (GMA). 
Tabela 3. Participação dos diferentes moinhos no processamento. (Porcentagem recebida em termos de arroz em casca), Uruguai.

\begin{tabular}{lccc}
\hline Moinho & \multicolumn{3}{c}{ Anos } \\
\cline { 2 - 4 } & $1974-76$ & $1977-79$ & 1975 \\
\hline SAMAN & 36,7 & 45,8 & 51,5 \\
COOPAR & 25,1 & 26,3 & 22,2 \\
ARROZAL 33 & 7,5 & 7,4 & 8,6 \\
CASARONE & 10,7 & 9,8 & 11,7 \\
CIPA & 2,8 & 1,5 & 2,7 \\
COPARROZ & 9,3 & 4,5 & 3,3 \\
OUtros & 7,9 & 4,7 & - \\
\hline
\end{tabular}

1 COPARROZ fechou ao fim do ano de 1979.

Fonte: Comision Sectorial del Arroz. 
A vinculação entre a produção, a industrialização e a comercialização é muito estreita. No caso das empresas agroindustriais, essas atividades encontram-se totalmente integradas em uma mesma unidade produtiva, processando ocasionalmente arroz de terceiros. SAMAN e COOPAR adquirem a totalidade do arroz de produtores independentes. Porém a vinculação agricultor-indústria é bem maior que o simples fato de uma transação de mercadorias; a indústria atua em aspectos financeiros, serve de avalistaperan te às instituições financeiras, realiza adiantamento de insumos; na pesquisa, financia projetos de pesquisa e assistência técnica; abastece insumos e bens de capital; dá terra e àgua para cultivo; e financia e assiste tecnicamente a construção de açudes para irrigação.

1.1.4. Tecnologia empregada

A tecnologia a nível industrial è relativamente simples e as empresas têm-se mantido atualizadas face aos processos tecnológicos utilizados no mundo. Analiza-se então, a tecnologia empregada na cultura.

No país, o reconhecimento da importância da tecnologia na cultura do arroz é relativamente tardia, se comparada com o restante das atividades agropecuärias, devido possivelmente à aptidão dos recursos naturais e a adaptação do modelo de produção introduzido do exterior. As primeiras 
pesquisas foram feitas pelas empresas particulares, sem a participação direta do Estado, e se referiam a avaliação de variedades visando a colocação no mercado externo.

O estado começà a participar na pesquisa de arroz tardiamente; como antecedente pode-se citar o Projeto Regional da Bacia da Laboa Mirim, 1965-70, que indicou a necessidade de uma estação experimental, que só começou a funcionar no começo dos anos 70 . Assim, surge à Estação Experimental do Este (EEE), iniciando-se um processo sistemātico de pesquisa nos diferentes aspectos da cultura. A ação da EEE esteve, desde suas origens, ligada ao setor privado, fato denunciado por numerosos trabalhos feitos em colaboração - Areas de Recuperação de rastrojos, EEE - ARROZAL 33, 1974; Plano de Prédios Pilotos, EEE - COOPAR, 1979; Sistema de Certificação de Sementes, EEE - Setor Privado Arrozeiro, 1977 - e que culmina em 1981 com a celebração do convēnio entre o Ministério de Agricultura e Pesca (MAP) e o Setor Privado Arrozeiro. Este tipo de convênio é único na realidade agropecuäria nacio nal.

Com relação as técnicas de produção de arroz no Uruguai, ela é toda realizada sob irrigação. Tradicionalmente, depois de dois anos sucessivos de cultivo, os campos ficam em descanso por seis a oito anos. Este descanso tem como finalidade, a diminuição da 
infestação de ervas daninhas que são difíceis de controlar e afetam muito os rendimentos. Durante o tempo sem cultura, os campos são aproveitados para pecuäriá, ainda assim, com baixa produtividade.

$\mathrm{Na}$ atualidade, quase esgotados os campos novos, somente um terço da cultura é feita neles. Nestes cam pos é possível obter-se bons rendimentos sem o uso de fertilizantes e herbicidas.

A impossibilidade de se fazer cultivo continuo, dá origem a um sistema de produção arroz-gado. Este sistema existe como tal, a nível físico sobre a unidade de solo, não acontecendo o mesmo a nível da empresa, uma vez que na maioria dos casos, os agentes produtivos são diferentes. 0 arroz é cultivado pelo agricultor que arrenda as terras e a pecuária é feita pelo dono da terra, quando o agricultor não realiza cultivo.

A escassez de terras agricultäveis e a necessidade de aumentar a produção, levou a intensificação do uso do solo mediante rotações mais curtas, onde depois do arroz, semeiam-se espēcies de pastagens de alta produtividade e introduzem-se a aração e a gradagem no verão.

Aspecto importante na cultura é o uso de àgua. A irrigação é por inundação na maior parte do ciclo da cultura, sendo a ägua tradicionalmente obtida de cursos naturais. A elevação da água é feita por bombeamento por 
meio de motores de combustão interna, o que resulta em distâncias não muito longas das fontes de ägua pelos custos associados. A alternativa para äreas distantes dos cursos ronge da água é construir açúdes nas partes àltas de pequenas bacias, para poder fazèr irrigação por gravidade. A irrigação a partir de açudes, tem se incrementado desde meados da década de 70 . No ano agrícola $75 / 76$ existiam oito barragens que irrigavam $2,3 \%$ da superfície cultivada; nos ültimos anos estão em funcionamento cerca de 50 barragens que irrigam mais de $30 \%$ da ärea. Os represamentos de ägua são investimentos vultosos o que obriga, na maioria dos casos, a encurtar o ciclo da rotação e assim conseguir amortizar a obra.

A preparação do solo é feita no inverno-primavera, em condições muito adversas e seguindo o contorno das taipas. Este tipo de trabalho, determina que a irrigação não possa ser feita até 60 dias da semeadura e que a àgua não fique distribuída uniformemente, o que ocasiona que a população de plantas seja pouco uniforme: Assim sendo, a competição com as ervas daninhas è pobre e os rendimentos são afetados. Atualmente é recomendada, e efetuada por alguns produtores, a preparação do solo no verãoloutono rompendo as taipas e nivelando. A sistematização é feita depois da semeadura. Este tipo de preparo permite, melhorar as condições onde a planta vai se desenvolver, boas estruturas de drenagem para facilitar a colheita e controlar excessos de chuva. Segundo estas recomendações a ärea de cul- 
tivo fica em boas condições, para uma vez levantada a cultura, estabelecer pastagens. Estas pastagens permitem aumentar a produção de carne em $400 \%$.

A mudança mais importante verificada na produção de arroz è o uso de grão"longo, tipo "patna". Hoje $90 \%$ da superfície é plantada com a variedade Blue Belze, originäria de Beumont, Texas, EUA, que tem grande adaptação às condições do Uruguai. Sua qualidade é muito apreciada no mercado internacional.

A fertilização é hoje uma prätica comum; $90 \%$ da superfície é fertilizada em doses relativamente altas de fósforo, mas o uso de nitrogênio não é tão difundido (Tabe1a 4). A àrea tratada com herbicidas é de aproxinadamente $40 \%$, correspondendo a àreas de campos velhos (Tabela 5).

A colheita, igualmente às demais tarefas da cultura, é totalmente mecanizada e é feita a granel. 0 grão é transportado diretamente para secagern nos moínhos e depois armazenado. 
22.

Tabela 4. Evolução do uso de fertilizante na cultura de arroz no Uruguai (Percentagem de ärea fertilizada em relação ao total de área plantada).

\begin{tabular}{ccc}
\hline Ano agricola & $\begin{array}{c}\text { Fertilização } \\
\text { basal }(N-P)\end{array}$ & $\begin{array}{c}\text { Fertilização } \\
\text { com uréia }\end{array}$ \\
\hline $1975 / 76$ & 72,6 & 31,9 \\
$1976 / 77$ & 62,4 & 32,0 \\
$1977 / 78$ & 59,6 & 45,5 \\
$1978 / 79$ & 62,0 & 30,1 \\
$1980 / 81$ & 70,0 & 49,1 \\
$1981 / 82$ & 86,0 & 77,7 \\
\hline
\end{tabular}

1. As formulações utilizadas são muito pobres em nitrogênio Fonte: $A C A$. 
23.

Tabela 5. Evolução do uso de herbicidas na Região Leste (Percentagem de ärea tratada em relação ao total de ārea plantada).

\begin{tabular}{cc}
\hline Ano Agrícola & Sup. tratada \\
\hline $1975 / 76$ & 7,9 \\
$1976 / 77$ & 5,6 \\
$1977 / 78$ & 17,0 \\
$1978 / 79$ & 12,8 \\
$1979 / 80$ & 26,2 \\
$1980 / 81$ & 35,1 \\
\hline
\end{tabular}

Fonte: $A C A$. 
1.1.5. Destino da produção

1.1.5.1. Mercado interno

Como já foi dito, o auto abastecimento do mercado interno foi alcançado em 1935. Este mercado absorve $50 \mathrm{mil}$ toneladas de arroz em casca, das quais $35 \mathrm{mil}$ são para consumo humano e $15 \mathrm{mil}$ para semente. A quantidade destinada ao consumo humano representa um consumo por habitante aproximadamente 10 quilogramas por ano de arroz branco (Tabela 6), que é baixo se comparado com outros países (Tabela 7).

1.1.5.2. Exportações

A partir de 1936 , o país exporta volumes cres centes de arroz que depois de 1950 tornam-se importartes. Nos últimos anos as exportações passam de cerca de $50 \%$ para $90 \%$ da produção nacional (Tabela 8), representando aproximadamente $2 \%$ do comércio mundial do cereal. 
25.

Tabela 6. Consumo anual e per capita de arroz branco no Uru guai, período 1972-1982.

\begin{tabular}{ccc}
\hline Ano & Consumo total & Consumo per capita \\
agrícola & (toneladas) & (quilogramas) \\
\hline $1972 / 73$ & 27.063 & 10,4 \\
$1973 / 74$ & 27.457 & 10,6 \\
$1974 / 75$ & 26.385 & 9,5 \\
$1975 / 76$ & 26.994 & 9,3 \\
$1976 / 77$ & 23.953 & 8,7 \\
$1977 / 73$ & 26.004 & 9,3 \\
$1978 / 79$ & 26.991 & 9,7 \\
$1979 / 80$ & 22.689 & 8,1 \\
$1980 / 81$ & 21.718 & 7,3 \\
$1981 / 82$ & 20.391 & 7,3 \\
\hline
\end{tabular}

Fonte: Comisión Sectorial del Arroz. 
26.

Tabela 7. Consumo per capita de arroz branco para algunspaí ses e regiões - 1950/52, 1961-63 e 1975 (Em quilogramas por pessoa e por anol.

\begin{tabular}{lccc}
\hline & Média & Média & 1975 \\
\hline Região país & $1950-52$ & $1961-63$ & 6 \\
Brgentina & 5 & 4 & 47 \\
Cuba & 33 & 44 & 43 \\
México & 57 & 50 & 6 \\
Japão & 4 & 5 & 103 \\
Estados Unidos & 104 & 117 & 6 \\
Europal & 2 & 3 & 3 \\
\hline
\end{tabular}

1. Para os períodos 1950-52 e 1961-63 somente inclue Europa 0cidental.

Fonte: SISTO, 1982. 
Tabela 3. Produção e exportação de arroz no Uruguai, 19651983.

\begin{tabular}{|c|c|c|c|}
\hline Anos & $\begin{array}{l}\text { Produção } \\
\text { (toneladas) }\end{array}$ & $\begin{array}{l}\text { Exportação } \\
\text { (tonel ladas) }\end{array}$ & $\%$ exportada \\
\hline 1965 & 90.042 & 26.094 & 29 \\
\hline 1966 & 83.746 & 62.622 & 75 \\
\hline 1967 & 115.617 & 57.165 & 49 \\
\hline 1968 & 104.456 & 29.432 & 28 \\
\hline 1969 & 134.496 & 99.844 & 74 \\
\hline 1970 & 133.611 & 51.451 & 37 \\
\hline 1971 & 122.153 & 96.553 & 79 \\
\hline 1972 & 127.995 & 61.712 & 48 \\
\hline 1973 & 136.917 & 87.913 & 64 \\
\hline 1974 & 157.940 & 79.940 & 51 \\
\hline 1975 & 188.535 & 137.392 & 73 \\
\hline 1976 & 216.521 & 137.134 & 63 \\
\hline 1977 & 228.276 & 171.297 & 75 \\
\hline 1978 & 225.646 & 140.078 & 62 \\
\hline 1979 & 247.973 & 228.790 & 92 \\
\hline 1980 & 304.975 & 200.243 & 62 \\
\hline 1981 & 335.034 & 290.763 & 37 \\
\hline 1982 & 373.785 & 251.320 & 67 \\
\hline 1983 & 390.460 & 317.670 & 81 \\
\hline
\end{tabular}


o Uruguai vende no segmento do comércio de arroz de grão longo de alta qualidade, liderado pelos Estados Unidos, e com destino a países com altos ingressos ou grande disponibilidade de divisas. Analizando o destinodas exportações uruguaianas, vê-se que existe coincidência entre os países aos quais vendem Uruguai e Estados Unidos, sendo que este último é o principal competidor no mercado externo (SISTO, 1982). Nos ültimos anos, a exportação de arroz vem sendo feita com maior grau de elaboração. De arroz semi-processado, passou-se a exportar arroz branco e a partir de 79, arroz parboiled. Esta evolução é muito similar à experimentada pelos Estados Unidos com dois anos de precedència.

Embora as exportações uruguaianas tenham.sido crescentes, o mais notório desta evolução è a ausência de mercados compradores estáveis. A Europa Ocidental pode ser considerada um mercado relativamente estável, ainda que ultimamente tenha reduzido suas compras. A América Latina surge como o mercado mais instável, fundamentalmente pelas vạriações mostradas pelo Brasil, que em alguns anos adquiriu a metade da exportação do Uruguai, e em outros anos quase nada. A Europa Oriental e Extremo oriente sãomercados compradores eventuais e de volumes pequenos. 0 mercado que tem aumentado sua importanncia, se bem que com oscilações, é o Oriente Médio, destacando-se o Irã, país ao qual foi vendido $60 \%$ das exportações en 1984 . Nas 
vendas à este país, OUruguai foi favorecido pelo conflito deste com os Estados Unidos; desde 1979 existe um convênio de longo prazo entre os governos do Uruguai e Irã para trocar arroz e outros produtos por petróleo. O mercádo nigeriano foi importante comprador de arroz parboilizado até 1984.

1.1.6. Politicas para o arroz

A definição das políticas destinadas à cultura, tem-se caracterizado por ser em geral, resultante de uma estreita interação entre o setor privado e o Estado. Esta interação manifesta-se atravēs da existência de instituições de integração entre as partes, na elaboração de convênios de cooperação recíproca, àsim como na formulação e promoção de propostas sobre aspectos concretos por parte dos grupos empresariais ao Estado. Este fato é possivel pela existência de associações empresariais consolidadas, ainda que tendo relações conflitivas entre elas, são capazes de fazer propostas conjuntas. Esta solidez na ação empresarial e a importância econômica alcançada pelo setor arrozeiro o seu grande poder de barganha.

$$
\text { As associações empresariais do setor são }
$$
duas: Asociación de Cultivadores de Apros (ACA), que agrupa os produtores agrícolas, criada em 1947; e a cimimial de Molinos Arroceros (GMA), formada pelas empresas industriais 
(exceto COOPAR S.A., que por sua origem de cooperativa tem -se mantido fora) criada em 1950. Em 1963 funda-se a Comissão Honoräria de Promoção Arrozeira na órbita do. Ministērio da Agricultura e com participação da ACA e GMA. Em 1973 passá a se denominar Comissão Setorial do Arroz, com participação também do Banco da República Oriental do Uruguai (BROU), Ministério de Indústria, Ministērio de Transporte, Ministērio de Agricultura, Ministērio de Economia e a Secretaria de Planejamento.

1.1.6.1. Politica de preços

o Uruguai è um dos poucos países no mundo que não aplica políticas de sustentação de preço para o arroz em casca. 0 preço ao produtor é fixado na CSA, mediante negociação entre as associações e representantes do governo. Os critērios considerados são preço internacional, custo agrícola e custo industrial. Em certo período, à CSA determinava o volume comercializado internamente e os preços. Os preços internos eram fixados abaixo dos preços internacionais para proteger o consumidor (0IKOS, 1977). Atualmente, os volumes e os preços internos estão liberados de controles. 
1.1.6.2. Polftica de crëdito

o setor arrozeiro é forte usuário de crëdito, de fontes públicas e privadas; de custeio agrícola, de capital de custeio na indústria, e de investimento (0IKOS, 1977). Em 1962 cria-se uma linha de crédito pelo BROU e este passa a ser a principal fonte de financiamento de custeio. Porém, devido a quantidade emprestada ser inferior aos gastos da cultura, os agricultores tem tido que complementar com fontes privadas, especialmente com adiantamento dos moinhos a conta da colheita (0IKOS, 1977). Para o ano agrícola 85/36 conseguiu-se, através de negociações entre o BROU e a ACA, que o crédito público atendesse a todas necessidades de custeio e fosse de mais fácil acesso. O banco oficial tem também linhas a médio prazo para maquinaria e outros investimentos. A nivel da indústria, o BroU apoia com crédito de custeio e adiantamento a conta das exportações.

\subsubsection{Política tributária}

o arroz é tributado, como todo o setor agropecuário, de forma indireta através dos insumos e bens de capital utilizados. No início de 1905 calculou-se que $20 \%$ dos custos diretos correspondiam a impostos indiretos (STENERI, 1986). A partir do ano agrícola $81 / 82$, o governo tem devolvido parte destes impostos no momento da exportação, 
dependendo das suas necessidades orçamentais. Hoje vigora a 7,2\% do preço $F O B$ por este conceito. Devido à integração vertical do setor, a totalidade da evolução é repassada aos produtores agrícolas.

1.1.6.4. Politica tecnológica

Jä foi dito que a característica principal do processo tecnológico no setor arrozeiro, tem sido a participação do setor privado na geração e difusão de tecnologia. O Estado incorpora-se ativamente em 1970, com a instalação da Estação Experimental do Este (EEE).

A colaboração entre o setor privado e o Estado culminou com a assinatura do Convênio de Cooperação Técnico-Econômica MAP - Setor Privado Arrozeiro - ACA, ARROZAL 33, CIPA S.A., SAMAN S.A.. Neste convênio estabelece-se que, "O setor privado cooperará com O MAP nos programas de pesquisa, melhoramento, sistemas de produção, sementes, etc., que sobre o arroz desenvolvem-se na EEE" (ARROZ, 1982 ).

1.1.6.5. Polfitica de comércio exterior

As importações de arroz estão taxadas em $10 \%$ no caso do arroz em casca e semi-processado, e $20 \%$ para o arroz beneficiado.

Até princípios dos anos 30 , a importação de 
máquinas agrícolas era livre de taxação. Este fato foi multo importante pela incidencia da maquinaria nos custos agrí colas.

Sem dūvida, o aspecto mais destacável da política dé comércio exterior aplicado ao arroz, nos ültimos anos, foi a realização de acordos comerciais com governos de outros países. Esta tem sido a maior e principal via de colocação da produção uruguaia. Assim foram feịtos acordos com o Irã, em intercâmbio por petróleo; com a Nigéria, por petróleo também e nos últimos tempos com o Brasil, no marco do Protocolo de Expansão Comercial (PEC).

E importante salientar que a aplicação do poder negociador do Estado é uma das principais reivindicações das associações quer de produtores, quer de industriais.

\subsection{Importância dos Estudos de Oferta}

Nos paises subdesenvolvidos o setor agropecuário é de grande importância, seja para produzir alimentos, seja para gerar divisas que permitam acelerar seus processos de crescimento. Este fato resulta em que os governos intervenham fortemente no setor, tanto através de politicas 
especificas, quanto através de políticas macroeconômicas, mas com marcados efeitos sobre a agricultura.

Para o delineamento dessas politicas é necessário conhecer as respostas que os produtores teriam face às mesmas. Os estudos das relações de oferta de produtos agrícolas desempenham um papel importante, na medida em que apontam elementos para determinar a direção e magnitude da resposta esperada dos produtores rurais a estimulos ou desestimulos. Esse conhecimento permite que os formuladores de políticas tomem decisões assistidos por previsões mais precisas.

No Brasil, tem-se efetuado, a partir dos anos sessenta, uma série de trabalhos na área sob consideração. Contrariamente, poucos esforços têm sido dedicados nesta direção, no Uruguai.

Dos trabalhos publicados no Brasil, a abrangência, quer geográfica quèr por culturas, é considerável. Existem assim, trabalhos a nível nacional, regional ou estadual e para as culturas mais importantes. Este tipo de estudos permitiu um aprimoramento metodológico para estimativas de oferta de produtos agrícolas.

1.3. objetivos

Este trabalho tem por objetivo geral anali- 
sar as relações de oferta agregada de arroz para o Uruguai. Os objetivos específicos são:

a) Estimar as elasticidades preço da oferta agregada de curto e longo prazo;

b) Estimar as relações de resposta a preço da área plantada a curto e longo prazo;

c) Estimar as relações de resposta a preço de rendimento físico da cultura a curto e longo prazo. 


\section{METODOLOGIA}

\subsection{Aspectos Teōricos e Estimação Empírica}

A oferta de um bem è entendida como a relação entre a quantidade oferecida, por unidade de tempo, para venda, aos alternativos preços desse produto, mantidos constantes os preços dos demais produtos alternativos, dos fatores de produção e as condições tecnológicas de produção.

A derivação da curva de oferta como uma relação funcional entre quantidade oferecida e preço, baseia- se na função de produção de cada firma. Admite-se que as decisões de "que", "quanto". e "como" produzir sejam resultantes do objetivo de maximização do lucro da firma. Admite-se também que a firma atua em um mercado de concorrência perfeita, o que implica que não tem dimensão suficiente para alterar os preços dos fatores e produtos. A firma é tomadora de preços e o que ajusta, são somente as quantidades.

A partir das condições de maximização da função de lucro, obtém-se a curva de oferta da firma como a 
parte ascendente da curva de custo marginal, a partir do ponto de cruzamento com o ponto mínimo da curva de custo variāvel mēdio. Seja:

$L=R T-C \quad$ onde $R T=\bar{P} Q$

$$
c=f(Q)+K
$$

onde $L$ é a função lucro; $R T$ é a receita total dependente de preços constantes $(\bar{P})$ e quantidade vendida (Q), e C éocusto total dependente do custo variaviel [f(Q)]. e do custo fixo (K). Então:

$L=\bar{P} Q-f(Q)-K$

A condição de primeira ordem para o māximo de uma função (neste caso a função lucro) è que a derivada primeira da função em relação à variável independente, seja igual a zero. Isto é:

d'L

$\frac{d L}{d Q}=\bar{P}-f^{\prime}(Q)=0 \quad$, pois

$\bar{P}=f^{\prime}(Q)$, onde $f^{\prime}(Q)$ é o custo marginal da firma, custo este entendido como a adição ao custo total decorrente da produção ter sido aumentada em uma unidade. Tem-se então que: 
$\overline{\mathrm{P}}=\mathrm{CMa}$.

Isto implica em que para maximizar o lucro a firma produzirá até que o custo adicional da última unidade seja igual ao preço determinado no mercado.

Para assegurar que a função atingiu o máximo é necessärio mais uma condição; que a derivada segunda seja menor que zero, isto é, que:

$\frac{d^{2} L}{d Q^{2}}<0$, então $-\frac{d^{2} f(Q)}{d Q^{2}}<0$, ou seja

$\frac{d^{2} f(Q)}{d Q^{2}}>0$ isto é, a curva de custo marginal deve ser crescente a partir do ponto em que a curva de custo marginal atinge o mínimo.

$\frac{d\left(\frac{f(Q)}{Q}\right)}{d Q}=\frac{Q f^{\prime}(Q)-f(Q)}{Q}=\frac{1}{Q}\left[f^{\prime} Q-\frac{f^{\prime}(Q)}{Q}\right]=0$

Para que essa expressão seja igual a zero é necessário que custo variāvel médio seja igual ao custo marginal, sempre que $Q>0$.

o ponto de custo variável médio mínimo 
chamado de ponto de fechamento da firma, porque preços meno res resultariam em perdas líquidas para a firma.

0 produtor então ofertará distintas quantidades dependendo do preço fixado no mercado do bem em questão.

A sensibilidade do produtor às variações de preços é medida pela elasticidade-preço, que exprime a relação de aumento (diminuição) proporcional (\%) dà produção face a um aumento (diminuição) proporcional (\%) do preço.

$$
\text { Assim: }
$$

$E P=\frac{\frac{d Q}{Q}}{\frac{d P}{P}}$

onde Ep é o coeficiente de elasticidade-preço da oferta; $\underline{Q}$ é a quantidade ofertada do produto.; e $\underline{p} \ddot{e}$ o preço de mercado do produto.

O desenvolvimento analítico antes feito è vālido para firmas produzindo só um produto e, por incluir um componente de custo fixo, representa curto prazo. Para derivar a curva de oferta no longo prazo, o procedimento é - mesmo, mas permitindo que todos os fatores de " produção estejam variando. Já a consideração de que a firma produz 
40.

vários produtos resulta em uma derivação da oferta bastante complexa (PASTORE, 1973; BARROS, 1985).

A oferta da indústria (neste caso a oferta agregada de arroz no Uruguai), serā a somatōría das curvas de oferta dos produtores individuais, que se pressupõe atuam em concorrência nos mercados de produto e fatores. Se a anälise fosse para o setor agrícola em seu conjunto, poder-se-ia observar curvas de oferta de fatores positivamente inclinadas. Este fato resultaria em que a oferta agregada não fosse mais a somatōria das ofertas individuais, já que aumentos de produção resultariam em maiores custos, o que deslocaria para cima as curvas de custo marginal.

Este desenvolvimento teōrico fundamenta as estimativas empiricas feitas a partir dos dados de produção observados.

E possivel derivar curvas de oferta partindo-se de funções de produção de grupos homogêneos de produtores. Estudo deste tipo foi realizado por CROCOMO (1974) para derivar funções de oferta de milho e soja.

A forma mais comum de se determinar funções de oferta é a partir de dados agregados para produção, preços e outras variáveis que se reputem como relevantes na anälise. Neste estudo, será feito desse modo, tentando determinar as relações de oferta agregada de arroz de estimativa do comportamento da àrea plantada e dos rendimentos físicos e suas determinantes. 


\subsection{Material}

As informações básicas para este trabalho são provenientes da Direción de Estadisticas Agropecuarias (DIEA); dos dados fornecidos pela Asociación de Cultivadores de Arroz, da Comisión Sectorial del Arroz e da Asociación de Industriales Arroceros, do Uruguai.

Os dados climáticos foram tomados da Direción General de Meteorologia, do Uruguai.

Para o deflacionamento dos preços utilizou-se o Indice Geral de Preços ao Consumidor publicado pela Direción General de Estadistica y Censos.

$$
0 \cdot \text { período analizado corresponde a } 1956 \text { - } 1936 .
$$

\subsection{Mëtodo}

Do referencial teórico desenvolvido e pressupondo a racionalidade economica dos produtores na tomada de decisões é necessärio determinar quais são os preços que o agente econômico leva em conta.

Por outro lado, já foi visto que a diferença entre curto e longo prazo é devida à existência ou não de fatores fixos. Na prática, e mais ainda na cultura sob estudo, os fatores não tem rāpida mobilidade no tempo, uma vez que a cultura de arroz irrigado requer vultosos investimentos. 
Estes dois fatos dão origem aos modelos de defasagens distribuidas, seja pela forma como são formadas as expectativas de preços, seja pela rigidez dos fatores no curto prazo. Os trabalhos revisados que analisam oferta.de produtos agrícolas (BRANDT, 1964, 1965, 1966; ROSSO, 1964; CARMO, 1974; TOYAMA, 1970; TCHIZAWA, 1973; ROJAS, 1973; RIBEIRO, 1974; REBELLO, 1973; LADEIRA, 1974; PASTORE, 1973; NAMEKATA, 1977; FERREIRA, 1974; ZOCKUN, 1978; SANTOS, 1972; SALARO, 1982; PINAZZA, 1978), consideram expectativas estáticas de preços e rigidez a curto prazo dos fatores. Dito de outra forma, os produtores consideram o preço de um determinado ano anterior para fazer suas previsões, mas a resposta não é imediata ao equilíbrio desejado, devido à rigidez de alguns fatores. 0 ano considerado para determinar o preço depende em grande medida se a cultura é anual ou perene.

As equações a serem estimadas, entretanto, não permitem distinguir qual dos mecanismos se acha presente, o que exige do pesquisador um bom conhecimento da realidade para a qual especifica o modelo. BARBOSA et ali (1979) discutem esta conclusão baseados em hipóteses alternativas para a parte estocástica das equações especificadas. A discussão deste aspecto escapa ao alcance deste estudo.

As duas hipöteses comentadas podem ser testadas conjuntamente em um sö modelo, podendo-se determinar 
43.

se existem fontes de defasagem. No caso positivo, não é possivel discriminar qual das fontes estão presente, devido à forma da equação reduzida que se estima. PASTORE (1973) comenta problemas resultantes deste tipo de modelo no sentido de acontecer a inclusão de mais uma fonte de multicolinearidade e também a perda de graus de liberdade e complexidade da forma reduzida, quando são considerados preços de outros produtos.

Neste trabalho pressupõe-se expectativas estáticas de preços e certa rigidez na mobilidade dos fatores de produção, com o preço no ano imediatamente anterior como expectativa de pre ço futuro. Na cultura sob estudo a rigidez poderia provir da não disponibilidade de terra própria; a necessidade de uma infraestrutura de irrigação que não é de rápida construção; a fatores institucionais, i.e. liberação de créditos e outros. GRILICHES (1967), elabora um modelo em que desenvolve os custos de ajustamento, diferenciando os custos do produtor estar fora do equilíbrio (perda de lucros) e o custo derivado da realocação dos fatores que tem de ser realizada para se voltar ao equilíbrio.

Passa-se agora a uma descrição mais detalhada do modelo de expectativas estáticas e rigidez no curto prazo dos fatores. 
2.3.1. Modelo envolvendo rigidez dos fatores a curto prazo

Baseado em constatações empiricas, NERLOVE (1956) observou que as elasticidades-preço de oférta obtidas atē então, eram demasiado pequenas quando consideradas na prática. Este autor caminhou nas duas direções apontadas anteriormente sugerindo modelos de defasagens distribuidas por meio dos quais é possível se obter elasticidades de curto e de longo prazo. Ao modelo em que as expectativas de preço são estáticas, mas que introduz a idéia de que as respostas a estímulos de preço não se esgotam em um só período, NERLOVE chamou de ajustamento parcial.

Assim uma variação de preço levaria a duas alterações na oferta. No longo prazo, a produção ajustar-se-ia de modo a atingir o equilibrio indicado pelo novo preço, atravēs de realocação nos fatores produtivos. Ho curto prazo, no período seguinte à vigéncia do novo preço, dar-se-ia um ajustamento em direção ao equilíbrio, mas restrito pela não perfeita mobilidade dos fatores.

Na Figura 3 ilustra-se a ocorrência desse fenômeno e como se obtém as duas curvas de oferta (e portanto duas elasticidades de ofertal, de curto e de longo prazo. 


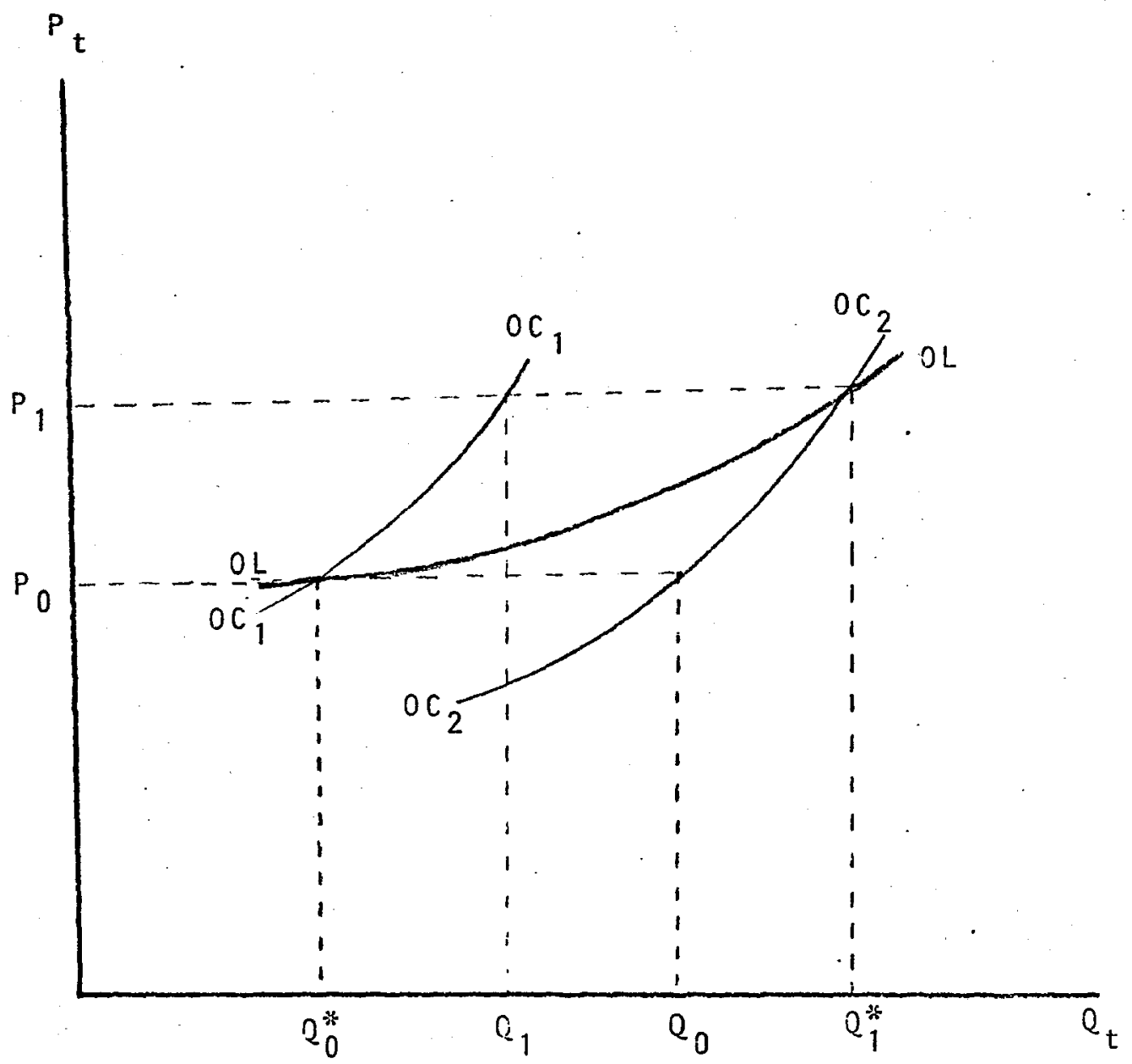

Figura 3. Curvas de oferta de curto e longo prazo. 
Partindo de uma situação de equilíbrio ao preço $P_{0}$ e quantidade oferecida $Q_{0}^{*}$, quando o preço aumenta para $P_{1}$, a quantidade ofertada observada é $Q_{1}$ e não $Q_{1}^{*}$ que seria a observada se não existisse rigidez na mobilidade dos fatores. Se o equilibrio inicial fosse a preço $P_{1}$ e quantidade ofertada $Q_{1}^{*}$, uma queda de preço a. $P_{0}$, resultaria em uma quantidade ofertada observada $Q_{0}$, maior que $Q_{0}^{*}$.

Ficam assim delineadas as curvas de oferta de curto prazo $\left(O C_{1}\right.$ e $\left.O C_{2}\right)$ e a de longo prazo $(O L)$ : Esta última é aquela que seria observada se transcorresse o tempo suficiente para remover todo tipo de rigidez. As de cur to prazo são aquelas observadas na prática. Na realidade obtém-se uma série de curvas de curto prazo, associadas a uma única curva de longo prazo.

0 modelo discutido pode ser expresso pelo sistema:

$Q_{t}^{*}=a_{0}+a_{1} P_{t-1}$

$Q_{t}-Q_{t-1}=r\left(Q_{t}^{*}-Q_{t-1}\right)$

sendo $Q_{t}^{*}$ a quantidade produzida no longo prazo ao preço $P_{t-1}$. A equação (2.5) mostra quanto do ajustamento desejado é $10-$ grado no curto prazo (neste caso o período seguinte); o coeficiente $\underline{r}$ expressa a proporção do ajustamento quando as variáveis estão na escala aritmética ou a elasticidadede ajus 
47.

tamento quando as variáveis estão na escala logarítmica. Em qualquer dos casos, seu valor será um nümero. entre zero e um. Se fosse um, o ajustamento seria total e o sistema reduzir-se-ia somente a equação (2.4). Se fosse zero não existiria nenhum ajustamento, pois não existiria resposta dos produtores a preço.

As equações (2.4) e (2.5) são as formas estruturais do modelo. Substituindo $(2.4) \mathrm{em}(2.5)$, chega-se à forma reduzida (2.6) capaz de ser estimada:

$Q_{t}=r a_{0}+r a_{1} P_{t-1}+(1-r) Q_{t-1}$

Esta equação não é mais uma relação funcional e sim uma relação entre variāveis observāveis cujos coe ficientes podem ser estimados estatisticamente.

Até aqui, para efeito de exemplificar a lógica do modelo, a variável dependente foi a quantidade produzida e a ünica variável independente foi o preço do produto defasado um período. Neste estudo a quantidade produzida (ou oferta agregada) será estimada a partir de duas equações: uma para àrea plantada e outra para rendimento fí sico da cultura onde são incluidas outras variáveis afetando ambas equações.

Para àrea plantada, obtem-se a forma reduzida genērica: 
$A_{t}=b_{1} a_{0}+b_{1} \sum_{j=1}^{k} a_{j} x_{j}+\left(1-b_{1}\right) A_{t-1}$

onde $A_{t}$ é área plantada; $A_{t-1}$ é área plantada no ano anterior; $k$ è o número de variäveis independentes $x_{j} ; a_{j}$ são os coeficientes das variáveis independentes e $b_{1}$ é o coeficiente de ajustamento.

Para rendimento, obtem-se a seguinte forma reduzida:

$R_{t}=b_{2} c_{0}+b_{2} \sum_{i=1}^{z} c_{i} x_{i}+\left(1-b_{2}\right) R_{t-1}$

onde $R_{t}$ é $\circ$ rendimento; $R_{t-1}$ o rendimento do ano anterior; $z$ é o nümero de variāveis independentes $x_{i}$; sendo $c_{i}$ os coeficientes destas variāveis independentes e $b_{2} \circ$ coeficiente de ajustamento.

Se as equações $(2.7)$ e (2.3) são estimadas com os logarítmos das variáveis, as elasticidades de ajustamento $b_{1}$ e $b_{2}$ são obtidas subtraindo-se as estimativas do coeficiente de regressão da variāvel dependente retardada, da unidade. As elasticidades-preço de longo prazo são obtidas pela divisão da estimativa do coeficiente de regressão da variável preço pelos coeficientes de ajustamento.

E necessário salientar que a inclusão da variável dependente retardada, como variável independente, tende a reduzir a autocorrelação nos resíduos e é possível que problemas de especificação do modelo (i.e., não inclu- 
são de variāveis relevantes), sejam mascarados pelos coeficientes daquela variável e dessa forma subestime-se o coeficiente de ajustamento que por sua vez resulta numa superestimação da elasticidade de longo prazo. E da maior importanncia neste tipo de modelos uma boa especificação dos mesmos, isto é, deve-se ser muito rigoroso na seleção das variāveis a serem incluidas. Para tal, deve-se recorrer à teoria económica da oferta. Dali pode-se derivar que a quantidade produzida de um produto depende do preço dele, do(s) preço(s) do(s) produto(s) que compete(m) pelos fatores de produção, dos próprios preços dos fatores, do nível tecnológico e de fatores não econômicos que afetam os processos biológicos.

o fato da cultura do arroz no Uruguai, apresentar comportamentos diferentes na sua evolução temporal, indicaria a conveniência de especificar um modelo que inclua variáveis binärias para testar a validade de separar o período sob estudo, em dois estágios. 0 ano de corte estaria situado na metade da década de setenta, pois foi a partir desse momento que as exportações passaram a crescer significativamente. Os pacotes tecnológicos gerados pela pesquisa foram adotados rapidamente, face aos requerimentos de se produzir a custos competitivos no mercado externo, assim como de se atender à exigências de qualidade desse no vo mercado em expansão. Com a inclusão destas variāveis binärias tenta-se mostrar uma mudança de comportamento, a- 
fetando o intercepto e a inclinação da função de oferta. Exemplos de uso de binārias neste tipo de modelos podem ser encontrados em.NAMEKATA (1977), ZOCKUN (1978) e SiMIñn $(1984)$.

A seguir os dois modelos a serem utilizados neste estudo, assim como a fundamentação de suas escolhas, são discutidos:

- Area plantada = f (área plantada defasada; preços defasado do produto; preço defasado do produto substituto; tendência).

$$
\begin{aligned}
A_{t}= & b_{1} a_{0}+\left(1+b_{1}\right) A_{t-1}+b_{1} a_{1} P_{t-1}+b_{1} a_{2} p_{g_{t-1}}+b_{1} a_{3} T+ \\
& +v_{1}
\end{aligned}
$$

As duas primeiras variāveis independentes deste modelo são incluidas por causa do modelo de ajustamento parcial com expectativas estáticas de preços e rigidez na mobilidade dos fatores.

Embora o arroz seja uma cultura fundamentalmente de exportação e não exista uma intervenção direta do governo na fixação do preço, não será considerado o preço internacional devido a que polfticas gerais (especificamente a cambial), fizeram com que o preço recebido pelos produtores não corresponda a esses preços internacionais. 
Devido à abrangência geográfica do estudo, à baixa produtividade das pastagens existentes e às características das terras nas quais se desenvolve a cultura do ar roz, o único produto competitivo é a criação de gado para corte. A variāvel a utilizar seria o preço do bezerro, mas, por falta de informação para a sērie de anos considerada, serà utilizado o preço do boi gordo como proxy.

Uma vez que o preço do boi seja relevante na explicação de área plantada, será usado o mesmo modelo, mas substituindo as variáveis preço do arroz e preço do gado pela variável preço relativo do boi/preço do arroz.

A variāvel tendência foi incluida com 0 intuito de atenuar os efeitos de impossibilidade de se obter uma especificação total do modelo; como expressa PASTORE - (1973), "Na verdade seria preferível incluir explicitamente as variáveis que provocam esses deslocamentos persistentes na oferta. Mas elas nem sempre são quantificáveis, de forma que a inclusão da variāvel tempo representa simplesmente um artificio utilizado para descrever esse comportamento, e justifica-se como uma medida de prudencia para evitar um viès de especificação no coeficiente de ajustamento".

- Rendimento físico $=f$ (rendimento defasado; preço defasado do produto; precipitação em setembro, outubro, novembro; tendência). 


$$
\begin{aligned}
R_{t} & =b_{2} c_{0}+\left(1-b_{2}\right) R_{t-1}+b_{2} c_{1} P_{t-1}+b_{2} c_{2} c h+b_{2} c_{3} T+ \\
& +v_{2}
\end{aligned}
$$

A precipitação nas datas de fim de preparo do solo e de semeadura é importante, na medida que é fato comprovado que o atraso no plantio provoca quedas relevantes no rendimento.

O deflator utilizado para preço será o Indice Geral de Preços ao Consumidor, como forma de eliminar as variações no nivel geral de preços.

A oferta agregada vai ser obtida pela identidade:

$Q_{t}=A_{t} \cdot R_{t}$

A especificação das variáveis endógenas e exögenas é:

$$
Q_{t}=\text { quantidade total produzida no ano } t \text {, em }
$$

quilogramas;

$$
\begin{aligned}
& A_{t}=\text { ärea plantada no ano } t, \text { em hectares; } \\
& R_{t}=\text { rendimento agrícola no ano } t \text {, em quilo }
\end{aligned}
$$

gramas pör hectare;

$$
\begin{aligned}
& A_{t-1}=\text { ärea plantada no ano } t-1 \text {, em hectare; } \\
& P_{t-1}=\text { preço real de arroz no ano } t-1 \text { (pre- }
\end{aligned}
$$

ços em 1973), em Nș (novos pesos) por tonelada; 
$\mathrm{P}_{\mathrm{t}-1}=$ preço real do boi gordo no ano $t-1$ (preços de 1973), em N\$ (novos pesos) por tonelada;

$$
\begin{aligned}
& P_{g} P_{a}=\frac{{ }_{g} g_{t-1}}{P_{t-1}} \\
& T=\text { ano } 1956 \text { igual } 56 \text {, até ano } 1986=36 ; \\
& R_{t-1}=\text { rendimento agrícola no ano } t-1, \text { em }
\end{aligned}
$$

quilogramas por hectare;

$$
\mathrm{Ch}=\text { precipitação pluviométrica nos meses de }
$$
setembro, outubro e novembro, ano $t-1$, em milimetros.

$$
\text { As hipóteses estabelecidas antecipadamente, }
$$

com base no suporte teórico e o conhecimento empírico, são:

$$
\begin{aligned}
& \left(1-b_{1}\right)>0 ; b_{1} \dot{a}_{1}>0 ; b_{1} a_{2}<0 ; b_{1} a_{3}>0 \\
& \left(1-b_{2}\right)>0 ; b_{2} c_{1}>0 ; b_{2} c_{2}<0 ; b_{2} c_{3}>0
\end{aligned}
$$

A inclusão da variável bināria no modelo de ajustamento parcial simples tem por objetivo testar que em determinado momento, as mudanças tecnológicas a nivel do produtor resultaram em diferențes respostas aos estimulos econômicos. Este fato implica em que a variāvel bināria de inclinação afeta a variável preço do produto defasado no modelo proposto.

Assim a partir das equações estruturais com ajustamento parcial para ärea plantada e rendimento, in- 
54.

cluindo as mencionadas variáveis binärias pode-se obter as equações reduzidas a serem estimadas.

$$
\begin{aligned}
& A_{t}^{*}=a_{0}+e D_{1}+a_{1} P_{t-1}+0_{1} D_{1} P_{t-1}+a_{2} P_{g_{t-1}}+a_{3} T^{*}+u_{t}(2.1 \\
& A_{t}-A_{t-1}=b_{3}\left(A_{t}^{*}-A_{t-1}\right)
\end{aligned}
$$

$$
A_{t}=\left(1-b_{3}\right) A_{t-1}+b_{3} A_{t}^{*}
$$

$$
\begin{aligned}
A_{t}= & \left(1-b_{3}\right) A_{t-1}+b_{3} a_{0}+b_{3} e_{1}+b_{3} a_{1} p_{t-1}+b_{3} 0_{1} D_{1} p_{t-1}+ \\
& +b_{3} a_{2} p_{g_{t-1}}+b_{3} a_{3}^{T}+b_{3} u_{t}
\end{aligned}
$$

$$
\begin{aligned}
A_{t}= & b_{3} a_{0}+b_{3} e D_{1}+b_{3} a_{1} p_{t-1}+b_{3} o_{1} D_{1} p_{t-1}+b_{3} a_{2} p_{g_{t-1}}+ \\
& +\left(1-b_{3}\right) A_{t-1}+b_{3} a_{3} T+b_{3} u_{t}
\end{aligned}
$$

Para rendimento agrícola, seguindo o mesmo procedimento, chega-se a:

$$
\begin{aligned}
R_{t}^{\prime}= & b_{4} c_{0}+b_{4} i D_{1}+b_{4} \dot{c}_{1} P_{t-1}+b_{4} s_{1} D_{1} p_{t-1}+b_{4} c_{2} c h+ \\
& +\left(1-b_{4}\right) R_{t-1}+b_{4} c_{3} T+b_{4} u_{t}
\end{aligned}
$$

As variáveis são definidas da mesma forma que no modelo anterior. No primeiro período, a variável binária toma valor zero; e no segundo, valor um.

Nos dois modelos até este momento desenvol- 
vidos tem-se duas equações e uma identidade. Neste estudo, trabalha-se com modelos uniequacionais, e não equações simultaneas, devido ao fato de que, o "como" produzir, a determinado pelas empresas agroindustriais que comercializam a produção, deixando pouca margem de decisão para o produtor.

Para se obter as estimativas dos coeficientes de regressão será utilizado o método dos mínimos quadrados ordinärios jā que as variāveis são prē-determinadas ou exógenas portanto as equações são exatamente identificadas.

Com base na estatística "t", verifica-se a significância dos parâmetros estimados, enquanto o grau de ajustamento da regressão é indicado pelo coeficiente de determinação multipla corrigida $\left(\bar{R}^{2}\right)$, que leva em conta o nümero de variäveis independentes em relação ao nümero de observações, o que permite fazer comparações entre regressões com distinto nümero de variāveis independentes e observações. Utiliza-se ainda estatística "F" para testar a hipōtese segundo a qual, as variāveis independentes são relevantes na explicação de variações em àrea plantada e rendimento.

Para indicar a existência ou não de' autocorrelação serial nos resíduos será usada a estatística "h" de Durbin (JOHNSTON, 1972). Este teste foi criado por 
Durbin para os casos em que aparece na regressão, a variàvel dependente defasada. 0 valor de "h" é dado por:

$h=r \sqrt{\frac{n}{1-n \bar{V}\left(b_{1}\right)}}$

onde $r$ é o estimador do coeficiente de autocorrelação dos resíduos de primeira ordem, e é igual a:

$$
r=\frac{\sum_{t=2}^{n} e_{t} e_{t-1}}{\sum_{t=1}^{n} e_{t}{ }^{2}}
$$

onde $e_{t}$ denota os resíduos de MMQO. Este estimador não - precisa ser calculado a parte uma vez que:

$$
r \cong 1-\frac{1}{2} d
$$

onde d è a estatística comum de Durbin-Watson. Então a estatística "h" fica:

$$
h=\left[1-\frac{1}{2} d\right] \sqrt{\frac{n}{1-n \hat{V}\left(b_{1}\right)}}
$$


onde $n$ è o número de observações e $\hat{V}\left(b_{1}\right)$ é a variância estimada do coeficiente de regressão da variável: dependente retardada.

Esta estatística é testada como distribuição normal; assim se $h>1.645$ deve-se rejeitar a hipótese de autocorrelação zero ao nível $5 \%$.

E importante salientar que este teste deve ser usado somente em grandes amostras $(n>30)$, uma vez que para as pequenas não são conhecidas suas propriedades.

\subsubsection{Estudo de não reversibilidade das funções de oferta}

HOUCK (1977) modifica a técnica proposta por WOLFRAM em 1971, para estudar a não-reversibilidade das funções de oferta. Estes estudos atestam o fato de que a resposta a preço é maior quando estes estão se elevando, que quando estão diminuindo, devido principalmente ao estoque do capital fixo necessário para efetivar a produção.

Se a àrea plantada (A) depende do preço do produto $(x)$ e ambos variam com o passar do tempo; a hipótese a ser testada é a de que um aumento em $\underline{x}$, tem um efeito diferente (maior) sobre $\underline{A}$, que quando ocorre uma queda em x. Assim pode-se escrever:

$\Delta A_{i}=a_{0}+a_{1} \Delta x_{i}^{\prime}+a_{2} \Delta x_{i}^{\prime \prime} \quad(i=1,2, \ldots, t)$ 
onde:

$$
\begin{aligned}
& \Delta A_{i}=A_{i}-A_{i-1} \\
& \Delta x_{i}=x_{i}-x_{i-1} \text { se } x_{i}>x_{i-1} \quad \text { e igual a zero em caso } \\
& \text { conträrio }
\end{aligned}
$$$$
\begin{gathered}
\Delta x_{i}^{\prime \prime}=x_{i}-x_{i-1} \quad \text { se } x_{i}<x_{i-1} \text { e igual a zero em caso } \\
\text { conträrio }
\end{gathered}
$$$$
\text { o valor num ponto qualquer da série é: }
$$

$A_{t}=A_{0}+\sum_{i=1}^{t} \Delta A_{i}$

onde $A_{0}$, é o valor inicial da série. A equação (2.22) pode ser expressa como:

$$
A_{t}-A_{0}=\sum_{i=1}^{t} \Delta A_{i}
$$

$$
\text { Substituindo-se a equação }(2.21) \text { em (2.23) e }
$$
simplificando, obtem-se:

$$
A_{t}-A_{0}=a_{0} t+a_{1}\left(\Sigma \Delta x_{i}^{\prime}\right)+a_{2}\left(\Sigma \Delta x_{i}^{\prime \prime}\right)
$$

Fazendo $A_{t}^{*}, R_{t}^{*}$ e $D_{t}^{*} i g u a l$ a $A_{t}-A_{0}, \Sigma \Delta x_{i}, e$ $\Sigma \Delta x_{i}^{\prime \prime}$ respectivamente, têm-se: 
$A_{t}^{*}=a_{0} t+a_{1} R_{t}^{*}+a_{2} D_{t}^{*}$

onde $R_{t}^{*}$ é a soma dos períodos de incremento em $\underline{x}$, desde o

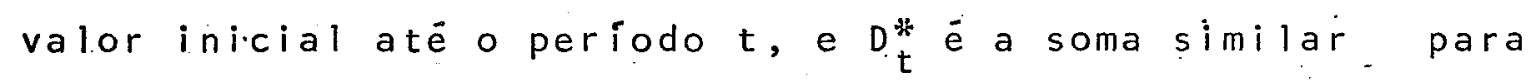
todos os períodos de decréscimo em $\underline{x}$. A variável $R_{t}^{*}$ é sempre positiva e $D_{\mathrm{t}}$ sempre negativa; se $a_{0}$. não é zero aparece na equação como coeficiente de tendência. Outras variàveis a incluir devem ser desviadas de seu valor inicial e depois efetuada a somatória.

HoUCK exemplifica o uso deste modelo em um trabalho de oferta de leite e outro de feijão nos Estados Unidos. No primeiro caso, a utilização das variáveis desviadas em relação ao valor inicial e a preço de leite defasado segmentada em períodos de crescimento e queda, resultou em diferentes elasticidades-preço. Os coeficientes estimados e os desvios das outras variáveis explicativas mo dificaram-se muito pouco, comparado com o modelo sem a inclusão de segmentação e desvios com respeito ao valor inicial. Os resultados permitiram rejeitar a hipótese nula de reversibilidade.

o autor chama a atenção para alguns problemas que podem surgir, quando se aplica este modelo. Um, é que a segmentação e a transformação temporal determinam a perda de dois graus de liberdade. Outro problema é que a correlação entre variáveis pode aumentar. 
No Brasil NAMEKATA (1977) utilizou o método de TWEETEN e QUANCE, e WOLFFRAM como modelo alternativo na estimativa da oferta de citros para o Estadóde São Paulo, constatando diferentes elasticidades-preço, parás períodos de preços crescentes ou decrescentes. 0 autor não obteve resultados estatisticamente significativos.

o modelo a ser especificado para testar a hipötese de não-reversibilidade utiliza as mesmas variäveis jā definidas. As variäveis preço do arroz ou relação preço gado-preço arroz são segmentadas como, explicado acima; as outras variāveis são transformadas em desíios de seus valores iniciais. Assim:

$A_{t}-A_{0}=\sum_{i=1}^{t} \Delta \dot{A}_{i}$

$A_{t}^{*}=b_{10} t+b_{11} R_{t}^{*}+b_{12} D_{t}^{*}+b_{13} A_{t-1}^{*}+b_{14} P_{g}^{*}+b_{15} T^{*}$

onde $t e ́$ a sērie de anos envolvidos; $R_{t}^{*}$ e $D_{t}^{*}$ são os segmentos de preços crescentes e decrescentes; $A_{t-1}^{*}$ é a somatória das àreas defasadas, desviadas do seu valor inicial; $\underset{\mathrm{g}}{\mathrm{g}}$ é a somatória dos preços originais do boi desviados do seu valor inicial; e $T^{*}$ é a somatōria da variāvel tendência ori ginal, desviada do seu valor inicial.

No caso de usar a variävel preço relativo, 
61.

esta é a variável que sofre a segmentação, e desaparece a variável $\mathrm{P}_{\mathrm{g}}^{*}$; mantendo o resto igual.

Este modelo vai ser testado somente para $\bar{a}-$ rea. 


\section{RESULTADOS}

o objetivo deste capítulo è apresentar a anālise dos resultados obtidos dos modelos específicados no ponto 2.3 para determinar as estimativas da oferta de arroz no Uruguai, no período de 1956 a 1956. 0 estudo baseou-se na pressuposição, de que a produção não sé ajusta de manei ra imediata aos estímulos derivados da estrutura de preços relativos, devido a uma certa rigidez, no curto prazo, na mobilidade dos recursos.

Admitindo-se que as expectativas são estäticas, os modelos foram especificados levando-se em consideração este fato, ou seja as variáveis independentes, preços do arroz e do produto substitutivo, são defasados em um ano.

Com o objetivo de aprofundar a análise, estimaram-se equações para àrea plantada e para rendimento cultural, separadamente, então $\quad \mathrm{Y}_{\mathrm{t}}=\mathrm{A}_{\mathrm{t}} \cdot \mathrm{R}_{\mathrm{t}}$, onde $Y_{t}$ é a produção en quilogramas. A $A_{t}$ é a área cultivada em hectares e $R_{t}$ é o rendimento cultural em quilogramas hectare. Este procedimento permite uma melhor observação dos 
fatores que influenciam a produção.

Em todos os modelos foram usadas as variáveis na forma aritmética e na. forma logarítmica, resultando que a segunda forma não melhorou os resultados. Assim, todas as equações são apresentadas na forma aritmética.

3.1. Modelo Simples de Ajustamento Parcial

3.1.1. Area

A equação selecionada para área plantada foi:

$$
\begin{array}{rl}
A_{t}= & -37363,3+0,81 A_{t-1}+1033,5 P_{t-1}-24,5 P_{g_{t-1}}+(-1,67) \\
& (-3,32) \quad(3,55) \quad(3,06) \quad \\
+ & 603,5 T \\
& (2,31) \\
& \\
\bar{R}^{2}=0,978 & F=334,3 \quad d=2,18 \quad h=-0,607
\end{array}
$$$$
\text { O elevado valor do } \overline{\mathrm{R}}^{2} \text { neste tipo de modelo }
$$
não é muito conclusivo, porque como já foi dito, a inclusão da variāvel dependente defasada como variável independente, resulta em geral em altos valores deste indicador.

0 teste " $t$ " de Student (entre parênteses na expressão 3.1) indica que os coeficientes de regressão par- 
64.

cial das variáveis indicadoras de área plantada defasada, preço do produto e tendencia, são significativos ao nível de pelo menos $1 \%$ de probabilidade, enquanto o coeficiente de regressão parcial do produto competitivo é significativo ao nivel de, pelo menos, $10 \%$ de probabilidade.

A estatística "d" de Durbin-Watson, da Ordem de 2,18, sugere ausência de correlação serial de primeira ordem nos resíduos, fato confirmado pelo valor da estatística "h" de Durbin, que resulta não significativo a $5 \%$.

o coeficiente de ärea defasada de 0,81 , indica que a resposta dos produtores não é muito rápida, já que resulta numia proporção de ajustamento de 0,19 ; o que estaria indicando uma forte restrição na mobilidade dos fatores de produção.

Os valores dos coeficientes de preço são coe rentes com a teoria. Os produtores aumentam a ärea plantada em resposta ao aumento do preço do arroz e tendem a diminui-la em conseqüencia de elẹvação de preço de produtos que concorrem com o uso do solo (no caso, a pecuária).

A alta significância da variável indicadora de tendencia, permite concluir que o modelo especificadomite variáveis importantes. Este fato foi previsto ao se discutir a metodologia, por isso não resulta surpreendente. A eliminação desta variável conduz a resultados anormais, 
tais como o valor do coeficiente da àrea defasada maior que um, contrariando a hipótese de que o coeficiente de ajustame to ë maior que zero e menor que um.

A correlação parcial entre a variävel indicadorá de tendência e àrea defasada, é alta. Porém, a significancia dos coeficientes dessas variáveis permite, em parte, superar o problema que essa correlação gera, ao interpretar os resultados (veja Apêndice 1).

obtido o coeficiente de ajustamento derivase a equação de oferta de longo prazo:

$$
A_{t}=-199280,5+5465,8 \mathrm{P}_{t-1}-128,9 \mathrm{P}_{\mathrm{g}_{\mathrm{t}-1}}+3176 \mathrm{~T}
$$

Levando em consideração os sinais e as significâncias dos coeficientes das variāveis $P_{t-1} e \quad P_{t-1}$, achou-se importante especificar o modelo com uma nova variāvel que inclua aquelas. Assim, define-se uma nova variävel preço relativo gado-arroz. 0 modelo de ajustamento parcial simples resultou:

$$
\begin{aligned}
& A_{t}=-32443,23+0,751 A_{t-1}-308,704 \mathrm{P}_{\mathrm{gPa}}+715,318 \mathrm{~T} \\
& (-2,914) \quad(8,495) \quad(-3,152) \quad(3,459) \\
& \bar{R}^{2}=0,979 \quad F=460,48 \quad d=2,25 \quad h=-0,79
\end{aligned}
$$


dos coeficientes são todas significativas a pelo menos $1 \%$. Mantem-se a alta significância da variável tendência pois continuam válidos os comentários feitos pará a especificação anterior.

Também aparece alta correlação entre as variāveis tendência e área defasada (veja Apêndice 1).

O coeficiente de ajustamento calculado a par tir da estimativa da variável área defasada, resultou um pouco maior que o anteriormente obtido, e é 0,249 . Isto é, os produtores somente ajustam uma quarta parte do que fariam, no longo prazo.

o teste "h" permite não rejeitar a hipótese de ausência de autocorrelação de primeira ordem nos resíduos.

A equação de oferta no longo prazo fica:

$A_{t}=-130294-1050,0 \mathrm{Pg}_{\mathrm{g}} \mathrm{P}+2433,05 \mathrm{~T}$

3.1.2. Rendimento

A especificação que mostrou melhor comportamento em termos estatísticos foi:

$$
\begin{aligned}
R_{t}= & 687,6-77,9 P_{t-1}-1,1 \mathrm{Ch}+58,8 T \\
& (0,73) \quad(-1,80) \quad(-1,57) \quad(5,87) \\
& \bar{R}^{2}=0,625 \quad F=17,7 \quad d=2,07
\end{aligned}
$$


Várias dificuldades surgiram para se determinar a melhor especificação para o rendimento devido, possivelmente, a falta de informações sobre as variáveis relevantes, tais como: o uso e preço de insumos e de bèns de capital.

0 rendimento defasado não apresentou significação em nenhum das tentativas feitàs, o que estaria mostrando em certa medida, o grau de variabilidade dos rendimentos culturais (Figura 4 ).

A equação resultante manifesta sinal negativo para a estimativa do coeficiente da variável preço do ano anterior, o que indicari, que os produtores, frente a subidas (quedas) de preço relaxariam (aprimorariam) as medidas de trato cultural. As outras variäveis apresentam os sinais esperados e não existem problemas de altas correlações en- tre as variáveis independentes. O teste de Durbin - Watson não evidencia sinais de autocorrelação de primeira ordem nos residuos.

Alguns comentários são feitos pelo fato de não se ter verificado a influência do rendimento do ano anterior, e obtido uma relação inversa entre rendimento e preço da cultura, pois contrariam as hipóteses expostas no capitulo anterior. 


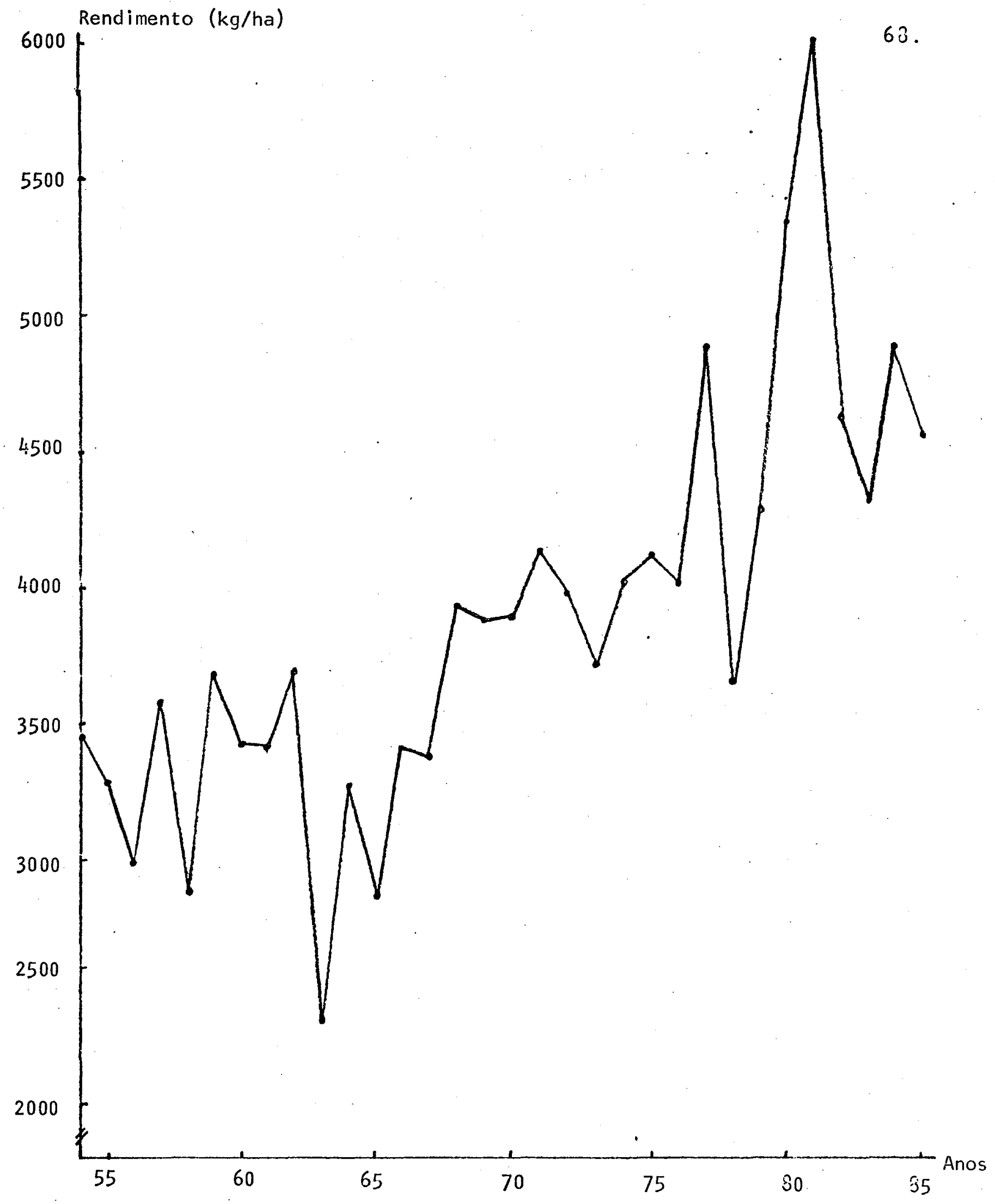

Figura 4. Evolução dos rendimentos de arroz no Uruguai. 
0 rendimento da cultura, se bem mostra uma tendência crescente, é muito variävel de ano em ano como visto na figura 4. Esta grande variabilidade, estäria fazendo com que o rendimento só do ano anterior não afetasse de forma importante o rendimento do ano seguinte. De algum modo a alta significancia da estimativa da variável tendencia indica que ela capta essas influências no longo prazo.

O sinal negativo, do coeficiente referente a preço de arroz defasado em um ano e sua significância (5\%) pode ser devido em parte à entrada e saída de produtores marginais quando ocorrem mudanças nos preços. Subidas de preço podem resultar em entrada de produtores novos, com conseqüente baixa nos rendimentos mëdios. 0 inverso ocorre face à uma queda no preço do produto.

De qualquer modo, não é possível extrair conclusões definitivas, face às carências de informação já apontadas .

3.2. Ajustamento Parcial com Variāveis Binárias

3.2.1. Area

0 fato de terem ocorrido algumas modificações no processo produtivo e na tendência de crescimento da área plantada, levam a considerar a possibilidade identifica- 
çãc dos momentos de tais ocorrências. Para isto, parece $\bar{u}-$ til recorrer ao uso de variāveis binärias, quer para verificar deslocamentos da curva de oferta, quer para deteriminar modificações na resposta relativa, ou as duas simultaneamente.

Na Figura 5, observa-se o que acontece com a àrea semeada ao longo do período sob estudo. No princípio da década de 70 a tendéncia de crescimento é muito mais pronunciada se comparada com o restante do período. Expressando graficamente a àrea plantada e os preços do arroz para os diferentes anos, pode-se tambēm extrair algumas observações interessantes. Recentemente, nos primeiros anos da década de 70 é que as àreas começam a se expandir rapidamente, impulsionadas por preços crescentes, que depois tiveram um comportamento irregular (Figura 6).

Assim sendo, tentou-se obter um melhor ajustamento, e por sua vez, eliminar a variāvel indicadora de tendência, pela inclusão de variävel binäria na primeira metade da década de 70. Depois de testar diferentes anos, chegou-se a tomar a produção do ano de 1975 , como ponto onde a binäria começa a ter valor um. 


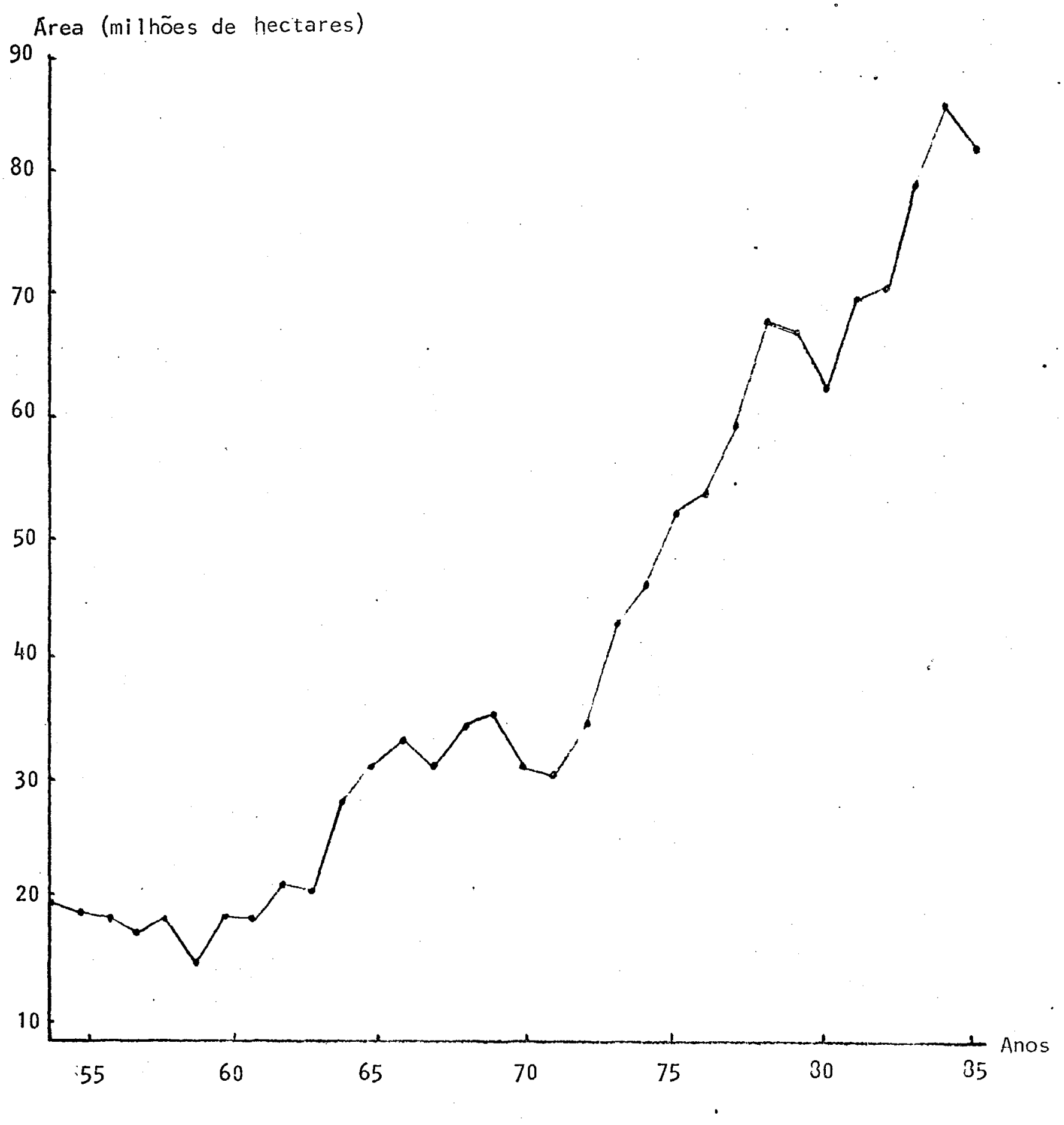

Figura 5. Evolução da área plantada no Uruguai. 


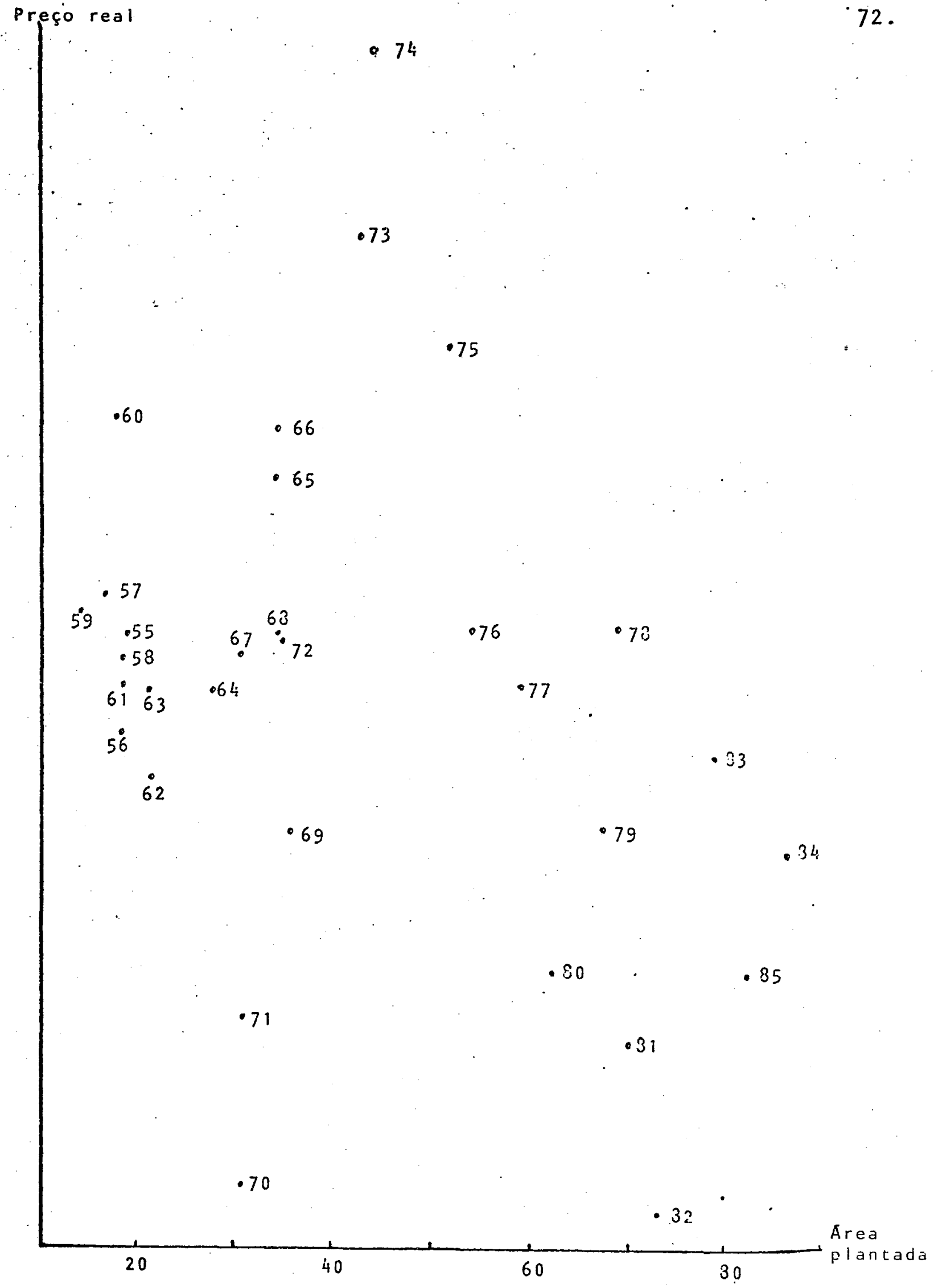

Figura ó. Preço real do arroz e área plantada por ano. 
No caso da ärea, não foi possível eliminar a variável tendência, já que sua exclusão provoca valores anormais do coeficiente da variável área defasada. A $\cdot$ equação ao final resultou:

$$
\begin{aligned}
& A_{t}=-44971,88+8476,72 \mathrm{D}+0,75 \mathrm{~A}_{t-1}+1491,58 \mathrm{P}_{t-1}- \\
& (-3,57) \quad(1,14) \quad(5,65) \quad(2,94) \\
& \begin{array}{ccc}
-910,52 D P_{t-1}-26,51 P_{g_{t-1}}+632,04 T \\
(-1,39) & (-1,56) & (3,07)
\end{array} \\
& \bar{R}^{2}=0,978 \quad F=223,09 \quad d=2,29 \quad h=-1,19
\end{aligned}
$$

Os coeficientes das variáveis preço de arroz defasado, ārea defasada e tendência são significativos a pelo menos $1 \%$. Já a mudança da inclinação é significati-va a pelo menos $10 \%$ e a mudança de intercepto a $20 \%$.

o fato importante aqui, são as diferenças nos coeficientes de preço defasado, indicando maior resposta ao estímulo dos preços no primeiro período.

o ajustamento da área é pouco maior que no modelo de retardamento sem binärias; mas também apresenta valores baixos $(0,25)$.

Para os dois períodos considerados as equações :

- Período 1 , onde $D=0$ 
74.

$$
\begin{aligned}
A_{t}= & -44971,83+0,75 A_{t-1}+1491,58 \mathrm{P}_{t-1}-26,51 \mathrm{P}_{\mathrm{g}_{\mathrm{t}-1}}+ \\
& +682,04 \mathrm{~T}
\end{aligned}
$$

- Período 2, onde $D=1$

$$
\begin{aligned}
A_{t}= & -33495,16+0,75 A_{t-1}+531,50 P_{t-1}-26,51 P_{g_{t-1}}+ \\
& +632,04 \mathrm{~T}
\end{aligned}
$$

Estes resultados, poderiam ser interpretados como no primeiro período da cultura no país, o preço foi uma determinante importante na indução de aumentos de área plantada; mas que a partir de um certo momento perde importância como indutor e outras variáveis (de certa maneira explicadas pela tendência) adquirem relevância. Mantem-se a alta correlação entre a variável área defasada e tendéncia e ao introduzir as variāveis binärias, resultam altas correlações entre elas e destas com a tendencia, o que estaria gerando um perigosorgrau de multicolonearidade] (veja Apêndice 1).

o teste "h" não permite rejeitar a hipótese de não autocorrelação de primeiro grau nos resíduos.

As curvas de oferta no longo prazo, com o coeficiente de ajustamento de 0,25 resultam:

- Período 1 , onde $D=0$ 


$$
A_{t}=-179387,52+5966,32 P_{t-1}-104,4 P_{g_{t-1}}+2723,16 \mathrm{~T}
$$

Período 2, onde $D=1$

$$
A_{t}=-133930,64+2326,32 P_{t-1}-104,4 P_{g_{t-1}}+2728,16 \mathrm{~T}
$$

\subsubsection{Rendimento}

Para o rendimento cultural, embora o poder explicativo continue baixo, os resultados são melhores em termos de eliminar a variāvel tendência. A equação escoIhida foi:

$$
\begin{aligned}
& R_{t}=5005,26+1069,6 \mathrm{D}-119,6 \mathrm{P}_{\mathrm{t}-1}-1,73 \mathrm{Ch} \\
& (11,98) \quad(6,29) \quad(-3,0) \quad(-2,62) \\
& \bar{R}^{2}=0,65 \quad F=19,9 \quad d=2,41
\end{aligned}
$$

Todos os coeficientes resultaram significativos a pelo menos $1 \%$. Estes resultados indicam que a partir de 1975 o rendimento da cultura subiu para um patamar maior, ainda que a inclinação não seja diferente.

Não apresentam problemas de multicolinearidade se observados os coeficientes de correlação parcial en tre as variáveis independentes (veja Apèndice 1) e também não se observa autocorrelação de primeira ordem dos resíduos. 
As equações resultantes para cada um dos períodos são:

- Período 1, onde $D=0$

$R_{t}=5005 ; 26-119,6 P_{t-1}-1,73 \mathrm{Ch}$

- Período 2, onde $D=1$

$R_{t}=6074,86-119,6 P_{t-1}-1,73 \mathrm{Ch}$

3.3. Hipóteses de Não Reversibilidade

Este modelo ténta medir, como já foi dito, se a resposta dos produtores é diferente quando os preços sobem ou descem. As variáveis a utilizar são originalmente as mesmas que no modelo de ajustamento parcial simples, mas seus valores são transformados como foi proposto na metodologia.

os resultados obtidos foram. inconsistentes com a construção do modelo. Como i lustração, apresentam-se duas equações em que a variável original tendência, foi excluida por considerar que em certa forma, ela ficava contemplada na especificação do modelo com o primeiro termo da equação apresentada no ítem 2.3.2.

Na primeira equação a variável segmentada è - preço da cultura e os resultados são: 


$$
\begin{aligned}
A_{t}^{*}= & 108,24 t+1206,36 R_{t}^{*}+478,78 D_{t}^{*}+0,07 A_{t-1}^{*}+ \\
& (0,15) \quad(1,587) \quad(0,528) \quad(4,03) \\
+ & 6,76 P_{g}^{*} \\
& (0,345) \\
& R^{2}=0,962 \quad F=316,93 \quad d=0,39 \quad h=3 ; 05
\end{aligned}
$$

Na segunda equação a variāvel segmentada é a relação de preços gado-arroz, e os resultados são:

$$
\begin{aligned}
& A_{t}^{*}=988,19 t-352,93 R_{t}^{*}-390,49 D_{t}^{*}+0,064 A_{t-1}^{*} \\
& (2,71) \quad(-2,15) \quad(-2,16) \quad(4,39) \\
& \bar{R}^{2}=0,963 \quad F=409,9 \quad d=1,15 \quad h=2,34
\end{aligned}
$$

Um fato que era esperado, mas que resultou em maior importância dó que o previsto é a alta correlação entre todas as variäveis independentes para as duas especificações (veja Apêndice 1).

Em ambos os casos, o teste "h" indica autocorrelação de primeira ordem nos resíduos.

Face a estes resultados, que distam muito dos apresentados por HoUCK, estes modelos não permiten tirar conclusões de proveito para a análise econômica. 


\subsection{Anālise Econômica dos Resultados}

os resultados inconsistentes com a teoria achados ao estimar as elasticidades preço do rendimento do arroz, parecem ser, em boa medida provenientes da falta de informação para trabalhar com as variāveis que pensava-se no inicio. Estes dados se referiam mais a variāveis de caráter tecnológico, tais como: luminosidade no momento de maturação do grão; excesso de chuva na colheita; e principalmente, custo e uso de insumos e fatores de produção.

o preço do produto, em certa medida, pode ter influência nas decisões dos produtores em adotarem técnicas de produção que maximizem seus lucros; mas não diz muito acerca do processo de geração dessas tecnologias e do que está se passando no mercado de insumos e fatores de produção.

Considerando a resposta dos produtores, em termos de àrea plantada, observou-se uma relação positiva; como esperado, entre ärea e preço da cultura. As elasticidades-preço calculadas para curto e longo prazo nos diferentes períodos e para as diferentes especificações são apresentadas nas Tabelas 9 e 10 . 
79.

Tabela 9. Estimativas de elasticidades-preço da área plantada para o arroz no Uruguai pelo modelo de ajustamento parcial. Período 1956-1996.

\begin{tabular}{lccc}
\hline Periodo: & Curto prazo & Longo prazo & coef.ajustamento \\
\hline $1956-1986$ & 0,209 & 1,101 & 0,19 \\
$1956-1975$ & 0,433 & 1,312 & 0,19 \\
$1976-1986$ & 0,125 & 0,656 & 0,19 \\
\hline
\end{tabular}

Tabela 10. Estimativas de elasticidades-preço da área plantada para o arroz no Uruguai pelo modelo de ajustamento parcial com variāveis binärias. Período 1956-1986.

\begin{tabular}{lccc}
\hline Período & Curto prazo & Longo prazo & . Coef.ajustamento \\
\hline $1956-1975$ & 0,490 & 1,978 & 0,25 \\
$1976-1986$ & 0,070 & 0,280 & 0,25 \\
\hline
\end{tabular}


Para a totalidade do perfodo sob estudo, a resposta dos produtores em ärea plantada foi inelástica no curto prazo e elästica no longo prazo. Isto era esperado devido a pouca mobilidade dos recursos de produção no curto prazo assinalado pelo coeficiente de ajustamento de 0,19 . Um aumento de $10 \%$ no preço real de arroż resulta em acréscimos na área plantada, de $2,1 \%$ no curto prazo e um aumento da àrea è de $11 \%$ no longo prazo, tudo o mais constante.

Ao dividir o período original em duas partes obteve-se elasticidades quase iguais no curto prazo e menores no longo prazo, principalmente no segundo período (Tabela 10). Ocoeficiente de ajustamento foi maior, mas ainda mostrando uma forte rigidez na mobilidade dos recursos. os baixos coeficientes de ajustamento achados não surpreen dem, pela maneira como é conduzida a cultura de arroz no Uruguai: é uma cultura irrigada por inundação, precisa de àto estoque de máquinas e com frequência é explorada em regime de parceria.

As baixas elasticidades obtidas no segundo período, podem-se dever ao fato de que foram outros fatores e não somente o preço, que fizeram com que os produtores aumentassem suas àreas.

Na Tabela 11 pode-se observar as elasticidades preço relativas ao gado-arroz da área plantada. As res postas são inelásticas quer no curto, quer no longo prazo 
e de sinal negativo uma vez que o preço do arroz fica denominador da relação de preços. Esta elastiçidade está indicando que se o preço do boi eleva-se $10 \%$ relativamente ao preço do arroz, a ärea plantada terá uma queda dé $1,4 \%$ no curto prazo, tudo o mais permanecendo constante.

As elasticidades preço relativo devem ser interpretadas com mais cautela pelo fato de se ter utilizado o preço do boi gordo como variável proxy da verdadeira atividade competitiva com o arroz que é a cria, e não a engorda de gado.

FITCHETT (1970) relata em seu trabalho, uma estimativa de elasticidade preço de curto prazo da área cuI tivada de arroz no intervalo de $0-0,4$ para os países subdesenvolvidos, o que coincide com os resultados deste trabaIho.

Para o Brasil tem-se desenvolvido uma série de trabalhos que de uma ou outra forma, tratam da oferta de arroz. A Tabela 12 é um resumo de alguns resultados de elasticidades obtidos por diferentes autores. Em geral, os valores não fogem muito dos obtidos neste trabalho. Os coeficientes de ajustamento em quase todos os casos são maiores que os observados para o Uruguai. Uma possível explicação para isso é que no Uruguai todo o arroz é irrigado por inundação, o que requer altos níveis de investimento em infraestrutura. 
Tabela 11. Estimativas de elasticidades-preço relativol de área plantada para o arroz no Uruguai pelo modelo de ajustamento parcial. Período 1956-1986.

\begin{tabular}{lccc}
\hline Período. & Curto prazo & Longo prazo & Coef.ajustamento \\
\hline $1956-1986$ & $-0,14$ & $-0,55$ & 0,249 \\
$1956-1975$ & $-0,22$ & $-0,90$ & 0,249 \\
$1976-1926$ & $-0,08$ & $-0,33$ & 0,249 \\
\hline
\end{tabular}

1 Preço do boi gordo/preço do arroz.

Tabela 12. Estimativas de elasticidades-preço calculadas por diferentes autores em diferentes anos.

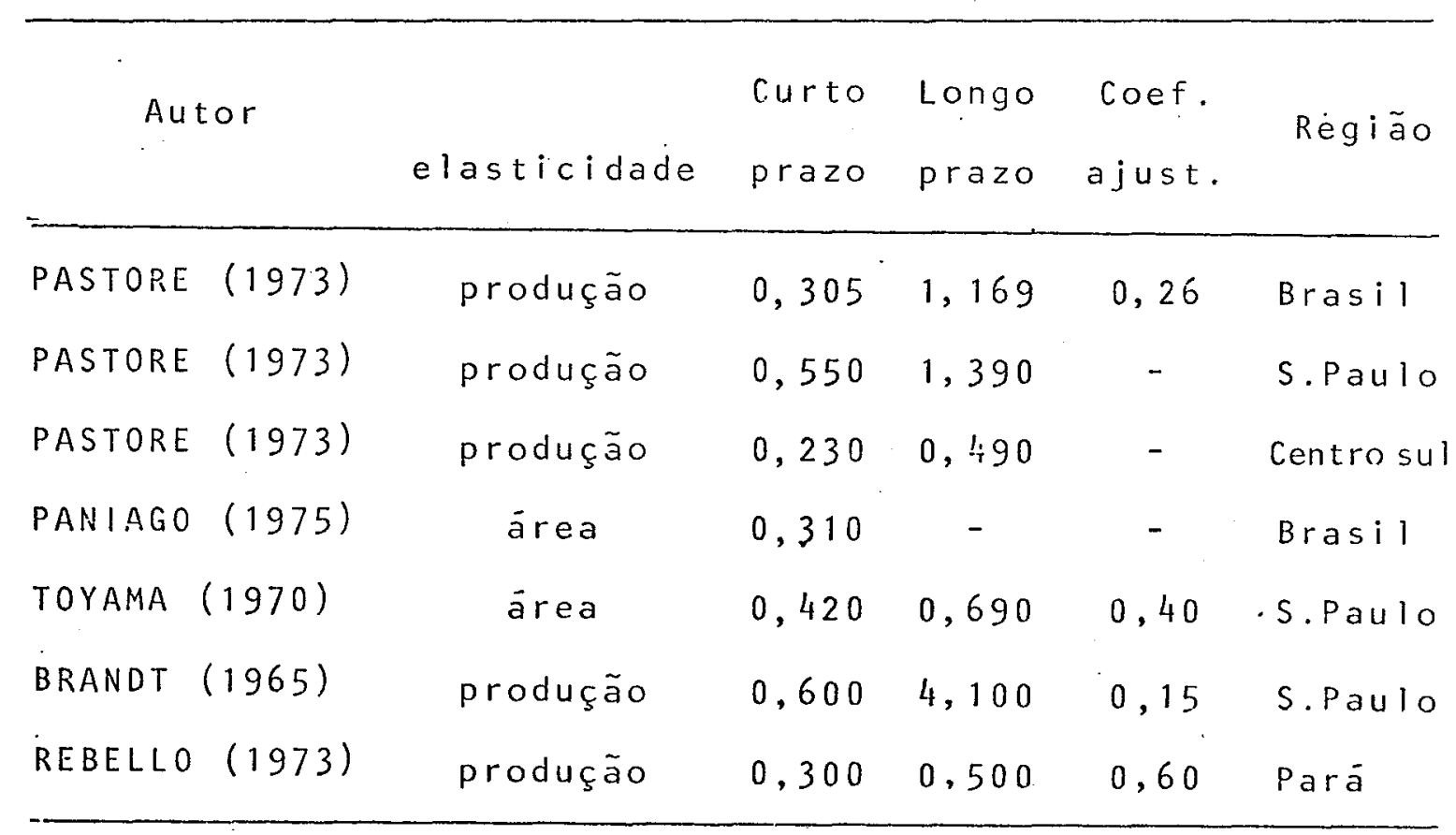


Dois trabalhos dos mencionados, PANIAGO e TOYAMA, tentaram estimar resposta do rendimento aos preços: nos dois casos, os coeficientes estimados para a variävel preço da cultura apresentava sinais negativos. Isto coincide com os resultados encon'trados neste estudo ao estimar elasticidade-preço para rendimento no Uruguai. Neste sentido, indica ser necessäria atenção maior para este problema. 
84.

4. CONCLUSÕES

A conclusão mais geral que se pode tirar das anālises feitas, é de que os orizicultores uruguaios têm comportamento racional, em termos da teoria exposta no inicio, frente aos estímulos económicos, aumentando as àreas quando os preços sobem. Esta resposta riáo é uniforme para todo o período sob estudo, pois a partir de 1975 ela se tor na mais inelästica, mesmo a curto prazo. Assim as elasticidades - preço estimadas para curto e longo prazo foram de 0,209 e 1,101 calculadas nas médias de'todo o periodo. Até 1975 as elasticidades-preço, estimadas tambëm-nas mëdias, resultaram em 0,49 e 1978. Já para o segundo período foram de 0,07 e 0,28 para curto e longo prazo, respectivamente. Estes resultados indicam que no segundo período, existiram outros fatores além do que o preço do arroz, que influiram na resposta dos pro dutores.

A hipōtese de forte rigidez na mobilidade dos recursos, suposta e não rejeitada, fez com que as elasticidades de longo prazo, fossem bem maiores que as de curto prazo. As estimativas resultantes deste trabalho, indicam que os produtores de arroz no Uruguai, não têm capacidade 
85.

de ajustar mais que uma quarta parte da área plantada do que fariam no longo prazo, se tudo, exceto o preço, se mantivesse constante.

A variāvel tendência mostrou uma foŕte influência na determinação da ärea plantada, o que indica provavelmente a existência de fatores não levados em conta no modelo na forma em que foi especificado. Não foi possível, ainda com a inclusão da variável bināria, eliminar a variāvel tendência do modelo, sem afetar a consistência do mesmo com a teoria e hipóteses sustentadas.

A atividade competitiva por recursos, expressada pelo preço do boi gordo, mostrou-se importante na determinação da àrea plantada de arroz; fato confirmado ao especificar o modelo com a relação de preços gado-arroz, como variável independente. A elasticidade-preço relativo da àrea plantada foi estimado em -0.14 e -0.55 para curto e longo prazo, respectivamente.

Uma vez estimadas as elasticidades-preço da ärea plantadạ, tentou-se testar se a. função àrea plantada poderia ser considerada não-reversivel, isto é, se as elasticidades-preço, quando os preços são crescentes, são diferentes das elasticidades-preço, quando os preços são decrescentes. 0 modelo elaborado como proposto por HOUCK, não apresentou os resultados esperados e não foi levado em consideração nas derivações de carāter econômico.

Para rendimento cultural obtiveram-se elas- 
ticidades-preço negativos, não consistentes com a teoria, possivelmente pelo fato de não contar com informação suficiente de variáveis de ordem climática e tecnológica. Devido a estes resultados não conclusivos, não foi estimada a elasticidade-preço de produção de arroz no Uruguai.

Para avançar no conhecimento de resposta dos produtores de arroz uruguaios a mudanças nos preços, é necessário em futuras pesquisas, avaliar o comportamento da totalidade do complexo agroindustrial. Especialmente no que se refere a determinação dos fatores que influenciam os rendimentos, deve-se analisar em profundidade, o processo de mudança tecnológica nos últimos anos, e qual o efeito da estrutura de preços relativos nesse processo. 
87.

REFERENCIAS BIBLIOGRÁFICAS

ALONSO, J.M. La producción de arroz em Uruguay: La dinámi ca de un cultivo de exportaciōn. Hontevideo. CINVE. 1982. $30 \mathrm{p}$.

BARBOSA, F.H. E WAIZBORT, E. Expectativa versus ajustamento no modelo de Nerlove de oferta e produtos agrícolas: Alguns resultados para o Brasil. Revista de Economia Ru ral, Brasilia, 17(4):163-131, 1979.

BARROS, G.S.A.C. Economia da comercialização agrícola, Piracicaba, ESALQ, Departamento de Economia e Sociologia Rural, 1935. 240 p. (mimeo)

BRANDT, S.A. et alii. Relações estruturais da oferta de al godão no Estado de São Paulo, São Paulo, 1964. (mimeo)

BRANDT, S.A. et alii. Elasticidades de ofertade batata, São Paulo, 1964. (mimeo)

BRANDT, S.A. et.alii. Estimativas de oferta de amendoim, arroz e mamona no Estado de São Paulo, São Paulo, 1965. (mimeo)

CAMARGO F.ILHO, W.P. Produção e comercialização de cebola no Brasil, Piracicaba, 1983. 84 p. (Mestrado- ESALO/ USP). 
CARMO, M.S.do. Anālise da demanda e da oferta de oleaginosas no Estado de São Paulo, Piracicaba, 1974. 159 p. (Mestrado - ESALQ/USP).

CHEBATAROF, N. Variedades de arroz em certificación en el Pais, CIAAB, Montevideo, Miscelanea n? 26, 1980.

CORSI, W. Regionalización agroclimatica del Uruguay para cultivos, CIAAB, Montevideo, Miscelanea n: 40, 1982.

CROCOMO, D.H.C. Oferta de milho e soja: Uma anälise a partir da função de produção, Piracicaba, 1974. 94 p. (Mes trado - ESALQ/USP).

FERREIRA, W.C. Oferta de culturas perenes: Pimenta-do-reino no Estado do Parā, Viçosa, 1974.. 91 p. (Mestrado Universidade Federal de Viçosa).

FITCHETT, D. The price responsiveness of farmers in Latin America. Papers and Reports. Hoscow, 1970.

GRILICHES, Z. Distributed lags: A survey. E.conomētrica, 35, jan. 1967 .

Houck, J.P. An approach to specifying journal of agricultural nonreversible functions. American Journal of Agricultural Economics, 59(3), august 1977:570-72, 1977 . JOHNSTON, J. Econometric Methods. New York, McGraw, Hill, 1972. $437 \mathrm{p}$.

LADEIRA, H.H. Avaliação econométrica da oferta de café em Minas Gerais, Viçosa, 1974. 103 p. (Mestrado - Universidade Federal de Viçosal. 
NAMEKATA; Y. Modelos alternativos de oferta: 0 caso dos citros no Estado de São Paulo, Viçosa, 1977. 81 p. (Mes trado - Universidade Federal de Viçosa).

NERLOVE, M. Estimates of the elasticities of supply of selected agricultural commodities. Journal of Farm . Economics (38), may 1956. p.496-509:

OIKOS-CONSULTAGRO. Diagnóstico de la producción arrocera, Montevideo, 1977.

PANIAGO, E. E SCHUH, G.E. Avaliação de políticas de preços para determinados produtos agrícolas no Brasil. In: ARAUJO, P.F.C. E SCHUH, G.E. Desenvolvimento da agricultura, Pioneira, 1975. $311 \mathrm{p}$.

PASTORE, A.C. A resposta da produção agrícola aos preços no Brasil, São Paulo, APEC, 1973. $173 \mathrm{p}$.

PINAZZA, A.ti. Oferta de cana-de-açūcar na Região Norte-ivor deste, Piracicaba, 1973. 69 p. (Mestrado - ESALQ/USP).

REBELLO, A.P.P. Estruturas de excedente comercializävel, $\underline{0}$ ferta e demanda de arroz em áreas selecionadas no Estado do Pará, Viçosa, 1973. 111 p. (Mestrado - Universidade Federal de Viçosa).

RIBEIRO, A.B. Estimativas de relações estruturais da oferta de cana-de-açúcar no Estado de Minas Gerais, Viçosa, 1974. 5.9 p. (Mestrado - Universidade Federal de Viçosa). 
ROSAS, M.B. Anālise de oferta de olho em Minas Gerais, Viçosa, 1973. 52 p. Mestrado - Universidade Federal de Viçosa).

ROSSO, W.J.T. Estimativas estruturais das relações de oferta de milho no Estado de llinas Gerais, 1944/62, Viçosa, 1972. 91 p. (Mestrado - Universidade Federal de Vi çosa).

SALARO, R. 0 mercado do feijão, oferta, demanda e intercâmbio, Salvador, 1982. 253 p. (Mestrado - Universidade Federal da Bahia).

SIMIÃo, S.A. A influência de fatores econômicos e regionais sobre a produção de mi tho no Estado do Paraná, Piracicaba, 1984. 136 p. (Mestrado - ESALQ/USP).

SISTO, M.1. Arroz: El mercado mundial como marco de las exportaciones Uruguayas. CINyE, Montevideo, 1982. 120 p.

STENERI, C. Costos de producción de arroz, safra $84 / 35$. Re vista Arroz, Montevideo $14(5), 1936$.

TACHIZAWA, E.H. Oferta agregada de algodão no Estado de São Paulo pelo modelo de ilerlove. Agricultura em São Paulo, 20 $(1,2): 211-35,1973$.

TOYAMA, N.K. E PESCARIN, R.M.C. Projeções da oferta agrícola do Esatdo de São Paulo. Agricultura em são Paulo, 17 $(9,10): 1-97,1970$. 
ZOCKUN, M.H.G.P. A expansão da soja no Brasil: Alguns as'pectos da produção, São Paulo, 1978. 228 p. (Mestrado-. FEA/USP). 


\section{APENDICE 1}

COEFICIENTES DE CORRELAÇÃO SIMPLES ENTRE AS VARIÁVEIS INDEPENDENTES PARA AS DIFERENTES ESPECIFICAÇÕES

\section{AJUSTAMENTO PARCIAL SIMPLES}

- Area Plantada

\begin{tabular}{|c|c|c|c|c|}
\hline & $A_{t-1}$ & $P_{t-1}$ & $P_{g_{t-1}}$ & $T$ \\
\hline$A_{t-1}$ & 1,000 & $-0,394$ & $-0,213$ & 0,943 \\
\hline$P_{t-1}$ & & 1,000 & 0,430 & $-0,324$ \\
\hline $\mathrm{P}_{\mathrm{g}_{\mathrm{t}-1}}$ & & & 1,000 & $-0,135$ \\
\hline & $A_{t-1}$ & $\mathrm{P}_{\mathrm{g}} \mathrm{P}_{\mathrm{a}}$ & $\mathrm{T}$ & \\
\hline$A_{t-1}$ & 1,000 & 0,137 & 0,943 & \\
\hline$\cdot P_{q} P_{a}$ & & 1,000 & 0,166 & \\
\hline
\end{tabular}

- Rendimento

$\begin{array}{cccc} & P_{t-1} & C h & T \\ P_{t-1} & 1,000 & -0,041 & 0,324 \\ C h & & 1,000 & -0,043\end{array}$




\section{AJUSTAMENTO PARCIAL COM VARIAVEIS BINARIAS}

\section{- Area Plantada}

$\begin{array}{lccrrrc} & A_{t-1} & P_{t-1} & D_{t-1} & P_{g_{t-1}} & D & T \\ A_{t-1} & 1,000 & -0,394 & -0,720 & -0,213 & 0,838 & 0,943 \\ P_{t-1} & & 1,000 & 0,123 & 0,430 & -0,163 & 0,324 \\ P_{t-1} & & & 1,000 & -0,200 & -0,928 & 0,714 \\ P_{t-1} & & & & 1,000 & -0,302 & -0,135 \\ { }_{D} & & & & & 1,000 & 0,344\end{array}$

- Rendimento

$\begin{array}{lccccc} & P_{t-1} & D P_{t-1} & C h & D & T \\ P_{t-1} & 1,000 & 0,123 & -0,041 & -0,168 & -0,324 \\ \text { DP }_{t-1} & & 1,000 & 0,108 & 0,929 & 0,714_{4} \\ C h & & & 1,000 & 0,101 & -0,048 \\ D & & & & 1,000 & 0,84_{4}\end{array}$




\section{- Com Preço Arroz e Preço Gado}

$\begin{array}{lcccccc} & \mathrm{t} & \mathrm{A}_{\mathrm{t}-1}^{*} & \mathrm{R}_{\mathrm{t}}^{*} & \mathrm{D}_{\mathrm{t}}^{*} & \underset{\mathrm{g}}{*} & \mathrm{~T} \\ \mathrm{t} & 1,000 & 0,901 & 0,972 & -0,986 & 0,979 & 0,972 \\ \mathrm{~A}_{\mathrm{t}-1} & & 1,000 & 0,877 & -0,935 & 0,819 & 0,976 \\ \mathrm{R}_{\mathrm{t}} & & & 1,000 & -0,953 & 0,975 & 0,951 \\ \mathrm{D}_{\mathrm{t}} & & & & 1,000 & -0,949 & -0,985 \\ \mathrm{P}_{\mathrm{g}} & & & & & 1,000 & 0,921\end{array}$

- Com Relação de Preços Gado-Arroz

$\begin{array}{lccccc} & t & A_{t-1} & R_{t} & D_{t} & T \\ t & 1,000 & 0,901 & 0,972 & -0,977 & 0,972 \\ A_{t-1} & & 1,000 & 0,926 & -0,936 & 0,976 \\ R_{t} & & & 1,000 & -0,964 & 0,972 \\ D_{t} & & & & 1,000 & -0,984\end{array}$


APENDICE 2

INFORMAÇÃO UTILIZADA

\begin{tabular}{|c|c|c|c|c|c|}
\hline Ano & $\begin{array}{l}\text { Area } \\
\text { (ha) }\end{array}$ & $\begin{array}{c}\text { Rendimento } \\
\qquad(\mathrm{kg} / \mathrm{ha})\end{array}$ & $\begin{array}{c}\text { Preço } \\
\text { arroz } \\
(N \$ 1973)\end{array}$ & $\begin{array}{l}\text { Preço gado } \\
\text { (N\$ 1973) }\end{array}$ & $\begin{array}{l}\text { Chuva } \\
\text { (mm) }\end{array}$ \\
\hline 1955 & 19794 & 3456 & 3,36 & 114,17 & 370,6 \\
\hline 1956 & 19399 & 3298 & 8,18 & 127,27 & 320,8 \\
\hline 1957 & 19071 & 1987 & 9,23 & 141,54 & 481,4 \\
\hline 1958 & 17137 & 3575 & 8,72 & 128,06 & 301,9 \\
\hline 1959 & 17800 & 2771 & 9,08 & 191,20 & 361,0 \\
\hline 1960 & 14453 & 3679 & 10,76 & 225,25 & 78,4 \\
\hline 1961 & 17790 & 3421 & 8,51 & 158,91 & 333,0 \\
\hline 1962 & 17788 & 3413 & 7,79 & 109,03 & 220,9 \\
\hline 1962 & 20986 & 3669 & $8,4 !$ & 128,81 & 724,9 \\
\hline 1964 & 20557 & 2293 & 8,45 & 155,80 & 253,5 \\
\hline 1965 & 27529 & 3271 & 10,20 & 184,20 & 274,6 \\
\hline 1966 & 30399 & 2746 & 10,61 & 213,99 & 349,3 \\
\hline 1967 & 33976 & 3403 & 8,75 & 161,23 & 264,6 \\
\hline 1968 & 30747 & 3397 & 3,93 & 103,53 & 340,6 \\
\hline 1969 & 34340 & 3917 & 7,22 & $1.27,08$ & 167,4 \\
\hline 1970 & 35691 & 3884 & 4,37 & 154,59 & 241,9 \\
\hline 1971 & 31408 & 3889 & 5,72 & 170,50 & 258,2 \\
\hline 1972 & 31146 & 4110 & 8,90 & 233,56 & 264,8 \\
\hline 1973 & 34540 & 3964 & 12,21 & 231,40 & 109,8 \\
\hline
\end{tabular}




\begin{tabular}{|c|c|c|c|c|c|}
\hline Ano & Ārea & Rendimento & $\begin{array}{l}\text { Preço } \\
\text { arroz }\end{array}$ & Preço gado & Chuva \\
\hline 1974 & 42660 & 3702 & 13,59 & 193,64 & 370,7 \\
\hline 1975 & 46923 & 4018 & 11,38 & 109,76 & 191,9 \\
\hline 1976 & 52327 & 4138 & 8,93 & 103,29 & 277,0 \\
\hline 1977 & 52840 & 4016 & 8,58 & 111,82 & 380,0 \\
\hline 1978 & $583 \hat{00}$ & 4865 & 8,94 & 115,62 & 373,7 \\
\hline 1979 & 68010 & 3646 & 7,33 & 241,85 & 375,8 \\
\hline 1980 & 67350 & 4270 & 6,11 & 137,20 & 247,7 \\
\hline 1981 & 62250 & 5306 & 5,51 & 91,23 & 304,0 \\
\hline 1982 & 69450 & 6031 & 4,10 & 69,46 & 232,0 \\
\hline 1983 & 70155 & 4606 & 7,83 & 113,33 & 594,3 \\
\hline 1984 & 78906 & 4313 & 7,11 & 169,06 & 237,3 \\
\hline 1985 & 86460 & 4866 & 6,11 & 135,72 & 310,9 \\
\hline 1986 & 82435 & 4550 & - & - & - \\
\hline
\end{tabular}

